\title{
Transcriptome analysis of the whitefly, Bemisia tabaci MEAM1 during feeding on tomato infected with the crinivirus, Tomato chlorosis virus, identifies a temporal shift in gene expression and differential regulation of novel orphan genes
}

Navneet Kaur ${ }^{1}$, Wenbo Chen², Yi Zheng ${ }^{2}$, Daniel K. Hasegawa ${ }^{3}$, Kai-Shu Ling ${ }^{3}$, Zhangjun Fei and William M. Wintermantel ${ }^{1 *}$

\begin{abstract}
Background: Whiteflies threaten agricultural crop production worldwide, are polyphagous in nature, and transmit hundreds of plant viruses. Little is known how whitefly gene expression is altered due to feeding on plants infected with a semipersistently transmitted virus. Tomato chlorosis virus (ToCV; genus Crinivirus, family Closteroviridae) is transmitted by the whitefly (Bemisia tabaci) in a semipersistent manner and infects several globally important agricultural and ornamental crops, including tomato.

Results: To determine changes in global gene regulation in whiteflies after feeding on tomato plants infected with a crinivirus (ToCV), comparative transcriptomic analysis was performed using RNA-Seq on whitefly (Bemisia tabaci MEAM1) populations after 24, 48, and $72 \mathrm{~h}$ acquisition access periods on either ToCV-infected or uninfected tomatoes. Significant differences in gene expression were detected between whiteflies fed on ToCV-infected tomato and those fed on uninfected tomato among the three feeding time periods: 447 up-regulated and 542 down-regulated at 24 h, 4 up-regulated and 7 down-regulated at 48 h, and 50 up-regulated and 160 down-regulated at $72 \mathrm{~h}$. Analysis revealed differential regulation of genes associated with metabolic pathways, signal transduction, transport and catabolism, receptors, glucose transporters, a-glucosidases, and the uric acid pathway in whiteflies fed on ToCV-infected tomatoes, as well as an abundance of differentially regulated novel orphan genes. Results demonstrate for the first time, a specific and temporally regulated response by the whitefly to feeding on a host plant infected with a semipersistently transmitted virus, and advance the understanding of the whitefly vector-virus interactions that facilitate virus transmission.

(Continued on next page)
\end{abstract}

\footnotetext{
* Correspondence: Bill.wintermantel@ars.usda.gov

'USDA-ARS, Crop Improvement and Protection Research, 1636 East Alisal

Street, Salinas, CA 93905, USA

Full list of author information is available at the end of the article
} 
(Continued from previous page)

Conclusion: Whitefly transmission of semipersistent viruses is believed to require specific interactions between the virus and its vector that allow binding of virus particles to factors within whitefly mouthparts. Results provide a broader understanding of the potential mechanism of crinivirus transmission by whitefly, aid in discerning genes or loci in whitefly that influence virus interactions or transmission, and subsequently facilitate development of novel, genetics-based control methods against whitefly and whitefly-transmitted viruses.

Keywords: Whitefly, Bemisia tabaci MEAM1 (biotype B), Tomato chlorosis virus, Crinivirus, RNA-Seq, Semipersistent transmission, Orphan genes, Gene expression

\section{Background}

The whitefly, Bemisia tabaci, is one of the most prevalent insect pests of agriculture in tropical and subtropical areas of the world, and transmits many plant viruses that result in serious crop losses estimated to range from several hundred million to billions of dollars worldwide annually [1]. This whitefly cryptic species complex can colonize over 1000 host plant species [2], and is known to transmit over 300 different viruses [3]. Bemisia tabaci is a complex of cryptic species, previously known as biotypes that differ from one another in host range, reproductive compatibility, insecticide resistance, endosymbiont composition, and virus transmissibility [4-12]. There are at least 39 cryptic species of B. tabaci recognized to date [13]. Among these, the Middle East Asia Minor 1 (MEAM1), formerly known as the B biotype or B. argentifolii [14], and the Mediterranean whitefly (MED), formerly known as the $\mathrm{Q}$ biotype, have become the most prevalent and agriculturally important cryptic species worldwide. This is in part due to their rapid dissemination throughout the world and apparent ability to adapt and displace other species [7, 15]. MEAM1 is arguably the most widely distributed of the $B$. tabaci cryptic species complex, and is known to transmit viruses from five distinct genera. Most of these are in the well-studied genus, Begomovirus, but MEAM1 can also transmit viruses from the genera Crinivirus, Carlavirus, Torradovirus, and Ipomovirus [3]. Furthermore, the mode of transmission varies among the different viruses.

Traditionally, plant virus transmission has been categorized as nonpersistent, persistent, and semipersistent. Nonpersistent viruses can be acquired rapidly by insect vectors during probing of plants with their stylets, and usually remain transmissible for only a few minutes to at most, a few hours following virus acquisition [16]. In contrast, persistent viruses, once acquired by the vector, are usually retained in transmissible form for the life of the insect. These viruses, as exemplified by whitefly transmitted viruses in the genus Begomovirus, are ingested by their insect vector, pass through the gut membrane and into the hemocoel, circulate through the hemocoel, and eventually accumulate in the salivary gland from which they are released during feeding, resulting in virus transmission [16-18]. Viruses classified as having a semipersistent mode of transmission associate with different locations within vector mouthparts dependent on the type of insect vector, and likely virus as well. Semipersistent viruses do not circulate throughout the body of the insect vector, and can be transmitted for only a few days [19].

New information is emerging on the location of crinivirus association with whitefly mouthparts $[19,20]$. Lettuce infectious yellows virus (Genus Crinivirus, Family Closteroviridae) was shown to associate with the anterior foregut, or cibarium of whitefly vectors [20-22], and a virus-encoded protein complex containing the LIYV minor coat protein is involved in this interaction [20-23]. There have not been any studies to date examining how whitefly gene expression changes in response to acquisition of a crinivirus during feeding. The objective of the current study was to determine whether gene expression differs between whiteflies that fed on plants infected with a crinivirus compared with those that fed on uninfected host plants. This would aid in clarifying whether crinivirus transmission results from a fortuitous association with pre-existing factors in whitefly mouthparts that bind the virus long enough to allow transmission, or if there is a deeper relationship in which the vector responds to the presence of the virus and the physiological changes it induces in an infected host plant with changes in its own gene expression that facilitate virus retention and transmission. In order to address this question, we examined the global gene expression changes that occur in $B$. tabaci MEAM1 during feeding on ToCV-infected tomato and uninfected tomato using high throughput RNA-Seq technology.

Analysis of differentially expressed genes (DEGs) associated with feeding on ToCV-infected plants compared to uninfected plants revealed several gene classes and specific biochemical pathways, including but not limited to orphan genes, glucose-transporters, $\alpha$-glucosidases, and genes associated with the uric acid pathway, metabolic pathways, signal transduction, transport and catabolism, and receptors. We also identified immune related genes associated with insect defense, and genes known to be involved in interactions with animal viruses. This transcriptome study establishes a fundamental understanding of the changes in whitefly gene expression in 
response to feeding on plants infected with criniviruses, and provides a baseline for comparison of differential gene expression in whitefly vectors feeding on plants infected by semipersistent viruses.

\section{Results}

\section{Transcriptome overview}

To understand global gene expression changes in the whitefly in response to ToCV, we performed RNA-Seq analysis on whiteflies that had been fed on ToCVinfected ('ToCV whiteflies') or uninfected tomato plants ('virus-free [VF] whiteflies') for three different feeding periods; 24,48 , and $72 \mathrm{~h}$. The RNA-Seq libraries generated 7.72-14.09 $\mathrm{M}$ raw reads per library, were processed to remove adapters, low quality reads, and reads from rRNA, mtDNA, and endosymbionts (Portiera, Hamiltonella, and Rickettsia), which resulted in $6.78-11.95 \mathrm{M}$ cleaned reads per library, with $75-86 \%$ mapped to the whitefly (Bemisia tabaci MEAM1) reference genome [24] (Additional file 1a). Pearson's correlation coefficients analysis showed data across different replications were highly reproducible (Additional file $1 \mathrm{~b}$ ).
DEGs in whiteflies associated with feeding on ToCV-infected tomato

Of the 15,664 genes predicted in the whitefly genome, 1,155 were found to be DEGs in ToCV whiteflies compared to VF whiteflies, including 989 genes (447 up-regulated and 542 down-regulated), 11 genes (4 up-regulated and 7 down-regulated), and 210 genes (50 up-regulated and 160 down-regulated) expressed differentially at $24 \mathrm{~h}, 48 \mathrm{~h}, 72 \mathrm{~h}$, respectively (Fig. 1a, Additional file 2). Although the majority of DEGs in ToCV whiteflies at different time points were distinct, there were some common among the three feeding periods (Fig. 1b). A principle component analysis (PCA) plot was generated for the 18 samples (Fig. 1c) that demonstrated clear separation between whiteflies that fed on healthy plants and ToCV-infected plants for both $24 \mathrm{~h}$ and $72 \mathrm{~h}$ treatments. The more limited differences with the $48 \mathrm{~h}$ samples reflected the very limited number of DEGs observed between treatments at this sampling time point, but results of the $48 \mathrm{~h}$ treatment were also highly correlated among treatments and replications (Additional file 1b). Further analysis of the DEGs at all time points in the whitefly associated with feeding on ToCV-infected

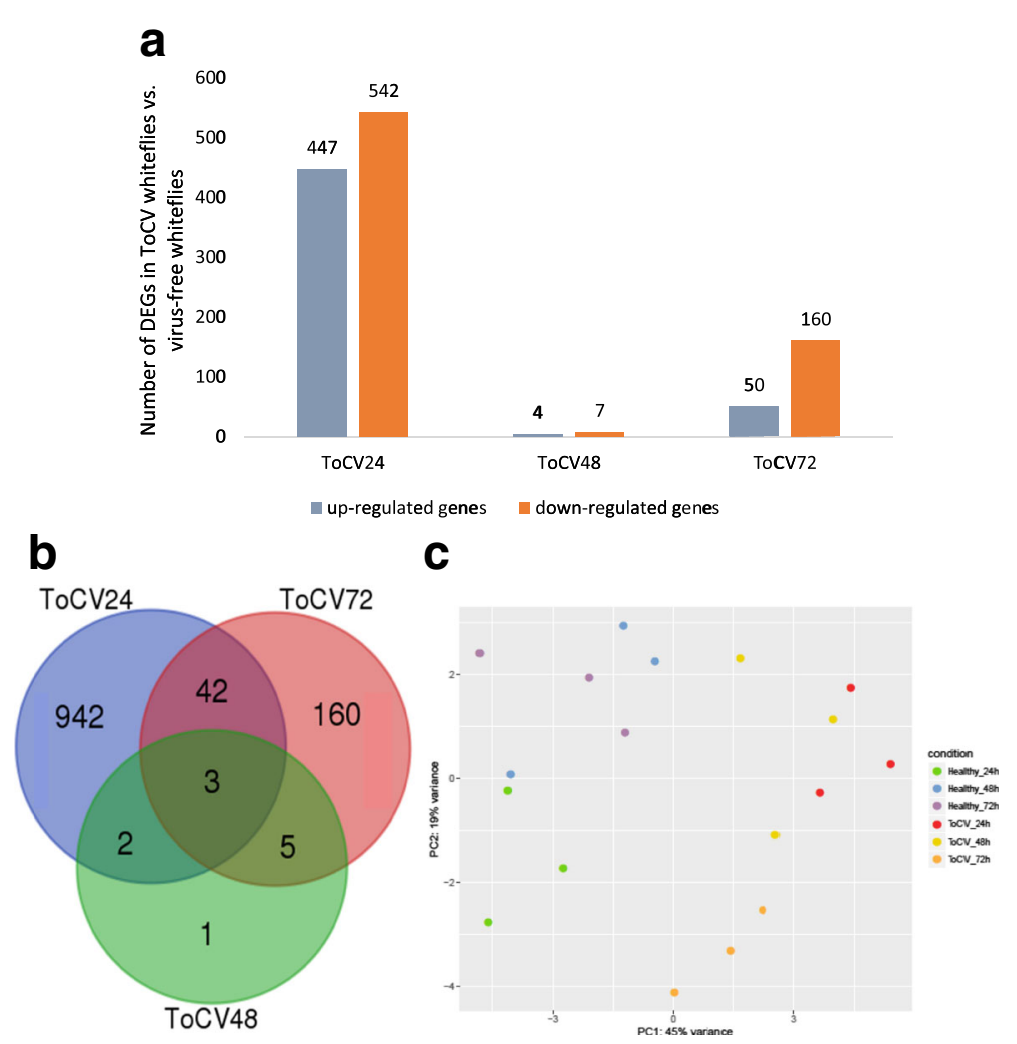

Fig. 1 Differentially expressed genes (DEGs) in whitefly, Bemisia tabaci MEAM1 following feeding on ToCV-infected (ToCV whiteflies) or uninfected (virus-free whiteflies) tomato plants for 24, 48, and 72 h; a Number of DEGs detected between ToCV whiteflies and virus-free whiteflies at three different feeding time points; $\mathbf{b}$ Venn-diagram showing unique and common DEGs in whitefly after feeding on ToCV-infected or uninfected tomato plants at three different feeding time points; c Principle component analysis (PCA) plot generated from 18 samples derived from virus free (healthy) or ToCV-whiteflies with three AAPs of 24, 48, and $72 \mathrm{~h}$ 
tomato plants revealed a large number of orphan genes, glucose transporters, $\alpha$-glucosidases, genes associated with the uric acid pathway, metabolic pathways, signal transduction, transport, catabolism, and receptors.

\section{Orphan genes}

Of the 1,155 DEGs between ToCV whiteflies and VF whiteflies, 337 showed no homology to any known genes or proteins in databases such as BLAST and InterPro, hence they are referred to as unknown or orphan genes specific to the whitefly. Large numbers of orphan genes were differentially regulated in ToCV whiteflies at $24 \mathrm{~h}$ (238 up-regulated and 84 down-regulated) compared with those from VF whiteflies, but only three orphan genes were found to have differential regulation at $48 \mathrm{~h}$ (one up-regulated and two down-regulated). Following the $72 \mathrm{~h}$ feeding period 85 orphan genes exhibited differential regulation (11 up-regulated and 74 down-regulated), although 34 out of 85 genes were also differentially regulated at $24 \mathrm{~h}$. Comparisons identified 21 orphan genes exhibiting differential regulation in ToCV whiteflies across all three feeding time points, although none exhibited significantly altered regulation at $48 \mathrm{~h}$ (Table 1). Eight out of 21 down-regulated orphan genes from ToCV whiteflies were present as a tandem cluster of repeats with significant similarity to one another on scaffold 17 in the whitefly genome [24]. These orphan genes are relatively short (267-501 bases), without introns, but with intact open reading frames, suggesting they are likely to be translated into proteins. Interestingly, BLAST analysis of these eight orphan genes present on scaffold 17 identified six genomic hits from nontranscribed regions corresponding to either the full-length or the 5' or 3' ends of orphan gene Bta04889. Remarkably, another set of 16 orphan genes present on scaffold 1103 were also found to have differential expression in whiteflies fed on ToCV-infected plants compared to those fed on uninfected plants (Additional file 3a). Six genomic hits with near identity to the full length or $3^{\prime}$ end of gene Bta00788, an orphan gene from scaffold 1103, were also found in the non-transcribed regions. Of these six nontranscribed genomic hits of Bta00788 regions, four were present as inverted repeats on scaffold 1103 in a region adjacent to Bta04889 (full-length genomic hits with 99\% sequence similarities) and two were present on scaffold 382 (3' end of the gene with $80 \%$ sequence identity) (Additional file $3 \mathrm{~b}$ ). We also examined the genomic hits of Bta04337, an orphan gene that was upregulated in ToCV whiteflies at $24 \mathrm{~h}$ and had the highest FPKM (fragments per kilobase of transcripts per

Table 1 Twenty-one common orphan genes significantly down-regulated in ToCV whiteflies following 24 and 72 h AAPs compared to virus-free whiteflies

\begin{tabular}{|c|c|c|c|c|c|c|}
\hline Gene & Strand & Intron & Gene length & CDS & Amino acid length & Location \\
\hline Bta00776 & Positive & No & 762 & 762 & 253 & Scaffold1103:822356..823117 \\
\hline Bta00778 & Positive & No & 1917 & 1917 & 638 & Scaffold1103:853502...855418 \\
\hline Bta00782 & Positive & No & 762 & 762 & 253 & Scaffold1103:863325..864086 \\
\hline Bta00786 & Positive & No & 666 & 666 & 221 & Scaffold1103:883608...884273 \\
\hline Bta00791 & Positive & Yes & 8199 & 1026 & 341 & Scaffold1103:927622..935820 \\
\hline Bta00821 & Positive & Yes & 29715 & 333 & 110 & Scaffold111:484171..513885 \\
\hline Bta04889 & Negative & No & 399 & 399 & 132 & Scaffold17:2533547..2533945 \\
\hline Bta04890 & Positive & No & 501 & 501 & 166 & Scaffold17:2535826..2536326 \\
\hline Bta04891 & Positive & No & 399 & 399 & 132 & Scaffold17:2541649..2542047 \\
\hline Bta04892 & Positive & No & 405 & 405 & 134 & Scaffold17:2547180..2547584 \\
\hline Bta04893 & Positive & No & 405 & 405 & 134 & Scaffold17:2550437..2550841 \\
\hline Bta04904 & Positive & No & 267 & 267 & 88 & Scaffold17:2821313..2821579 \\
\hline Bta04923 & Positive & No & 405 & 405 & 134 & Scaffold17:3256245..3256649 \\
\hline Bta04929 & Positive & No & 405 & 405 & 134 & Scaffold17:3520541..3520945 \\
\hline Bta08354 & Positive & Yes & 11999 & 2481 & 826 & Scaffold320:2336876..2348874 \\
\hline Bta09022 & Positive & Yes & 10221 & 4524 & 1507 & Scaffold338:275546..285766 \\
\hline Bta09026 & Positive & Yes & 9788 & 4338 & 1445 & Scaffold338:319459..329246 \\
\hline Bta09957 & Positive & No & 768 & 768 & 255 & Scaffold382:555931..556698 \\
\hline Bta14115 & Negative & No & 522 & 522 & 173 & Scaffold73:1576252...1576773 \\
\hline Bta14126 & Positive & No & 570 & 570 & 189 & Scaffold73:1855693..1856262 \\
\hline Bta15275 & Negative & No & 927 & 927 & 308 & Scaffold942:232434..233360 \\
\hline
\end{tabular}


million mapped reads) values in ToCV whiteflies $(12,317)$ compared with VF whiteflies $(6,048)$ and FC (fold change $)=2.05$ with $p$-value $=2.39 \mathrm{E}-09$. BLAST analysis of Bta04337 showed one significant genomic hit on a non-transcribed region with $99 \%$ identity at the nucleotide level, and this DNA sequence is present $\sim 7 \mathrm{~kb}$ upstream of Bta04337 on the same scaffold 1647. The second genomic hit for Bta04337 was found on the coding sequence regions of another orphan gene, Bta02258 (with 79-89\% sequence identities), and contains seven introns. A significant number of orphan genes are present in diverse organisms, including fungiSacharomyces, fruit fly-Drosophila, plant-Arabidopsis and human-Homo. These genes are implicated in human disease, species-specific adaptive processes, host-parasite interactions, and interactions with the environment [25-27], suggesting the possibility of an important role or even interactions involving differentially regulated orphan genes in whitefly associated with feeding on ToCV-infected host plants.

\section{Glucose transporters and a-glucosidases}

Ten and 15 unique glucose transporter and $\alpha$-glucosidase genes, respectively were differentially regulated in ToCV whiteflies compared with VF whiteflies (Table 2). Among 15 unique $\alpha$-glucosidases, only the expression of Bta14422 was found to be significantly down-regulated in all three feeding periods. This suggests an important role for glucose transporters and $\alpha$-glucosidases in the whitefly's response to feeding on ToCV-infected plants.

\section{Most abundant DEGs with high FPKM and FC values}

To identify the differentially regulated genes with the greatest FC differences and the highest FPKM values between whiteflies fed on ToCV-infected plants and uninfected plants for each feeding period, more stringent criteria were used to filter genes. Using these stringent criteria (FPKM values $>10, \mathrm{FC} \geq 2$ and a $p$-value $<0.05$ ), we identified significantly increased expression levels for 259, 2, and 16 genes in whiteflies fed on ToCV-infected tomato during the feeding periods of $24 \mathrm{~h}, 48 \mathrm{~h}$, and $72 \mathrm{~h}$, respectively, compared with whiteflies fed on uninfected tomato plants (Table 3). The genes exhibiting the greatest up-regulation in whiteflies fed on ToCVinfected plants after 24, 48, and $72 \mathrm{~h}$ were Bta13784 (orphan gene, $\mathrm{FC}=3.8, p$-value $=0.0001)$, Bta14011 (2-oxy4hydroxy-4-carboxy-5-ureidoimidazoline "OHCU" decarboxylase, $\mathrm{FC}=2.37, p$-value $=0.043$, and Bta15430 (uricase, $\quad \mathrm{FC}=3.39, \quad p$-value $=0.0008$ ), respectively (Table 3). Both $\mathrm{OHCU}$ decarboxylase and uricase play crucial roles in conversion of uric acid to allantoin in the uric acid pathway [28]. The ten most differentially up-regulated genes in ToCV whiteflies at $24 \mathrm{~h}$ (Table 3) all encoded unknown proteins (orphan genes) except for Bta02212, the fourth-most up-regulated gene in this treatment, which encodes a FLYWCH and MULE domain containing protein $(\mathrm{FC}=3.2, p$-value $=0.0001)$. FLYWCH is a type of zinc finger transcription factor that belongs to the $\mathrm{C} 2 \mathrm{H} 2$ class [29] and MULE is mutator-like element that functions as a transposase [30]. Among the 16 genes significantly up-regulated in whiteflies at $72 \mathrm{~h}$, were again two genes related to the uric acid pathway: Bta15430 and Bta14011, which encode Uricase and $\mathrm{OHCU}$-decarboxylase, respectively. Both genes showed over-expression in ToCV whiteflies with FC of 3.39 and 3.21, respectively and significant $p$-values (Table 3 ). Further analysis of up-regulated genes in whiteflies after a $72 \mathrm{~h}$ AAP on ToCV-infected tomato revealed that Bta09595, phosphoribosylformylglycinamidine cyclo-ligase is also related to the uric acid pathway. This gene is involved in the biosynthesis of purine nucleotides. Purines are precursors for components of the uric acid pathway [31]. Of the three up-regulated genes from the uric acid pathway in ToCV whiteflies at $72 \mathrm{~h}$, one gene, OHCUdecarboxylase was also up-regulated at $48 \mathrm{~h}$ with a $\mathrm{FC}=$ $2.37, p$-value $=0.043$ (Table 3$)$.

There were 271,3 , and 110 down-regulated genes at $24 \mathrm{~h}, 48 \mathrm{~h}$, and $72 \mathrm{~h}$, respectively in ToCV whiteflies compared to VF whiteflies. As was found with upregulated genes, the greatest expression differences between whiteflies that fed on ToCV-infected plants and those that fed on uninfected plants occurred after AAPs of 24 and $72 \mathrm{~h}$, whereas only a minimal number of significant differences were identified when whiteflies were given an AAP of $48 \mathrm{~h}$.

To further understand the roles of these downregulated genes in ToCV-infected whiteflies, we examined the roles of their homologs in other insect species. For perspective, 10 of the 271 most down-regulated genes in ToCV whiteflies at $24 \mathrm{~h}$ are listed in Table 4. Bta15563 (Vitellogenin-B, FC $=0.15, p$-value $=6.12 \mathrm{E}-10$ ) was the most down-regulated gene in $\mathrm{ToCV}$ whiteflies at $24 \mathrm{~h}$. Vitellogenins play roles in high fecundity, longer lifespan, housekeeping, as well as increased oxidative stress resistance in other insects [32, 33]. The second most down-regulated gene was Bta13640 (chemosensory protein, $\mathrm{FC}=0.17, p$-value $=1.13 \mathrm{E}-09$ ) which is known to be expressed in the antennae of insects, and is involved in sensing of environmental signals by triggering chemical-signal transduction [34]. Among the 10 most down-regulated genes in ToCV whiteflies at $24 \mathrm{~h}$, four genes were classified as having housekeeping roles, including the vitellogenin-B (Bta15563), glycerol-3-phosphate dehydrogenase (Bta08821), heat shock protein 70 (Bta02903), and a transcription elongation factor $B$ polypeptide, ubiquitin-related protein (Bta07359). The 48 h AAP resulted in only three genes showing significant downregulation compared to VF whiteflies: Bta13864 (Gamma 
Table 2 Genes encoding glucose transporters (a), a-glucosidases (b), and that are associated with the uric acid pathway (c) showing significant expression differences between whiteflies fed on ToCV-infected and uninfected tomato leaves for 24,48 , or $72 \mathrm{~h}$

\begin{tabular}{|c|c|c|c|c|c|}
\hline \multicolumn{6}{|c|}{ a) Glucose transporter genes } \\
\hline Gene ID & Gene name & VF24 $4^{a}$ & ToCv24 & $\mathrm{FC}^{\mathrm{C}}$ & adjusted $\mathrm{p}$ \\
\hline Bta11865 & Facilitated glucose transporter member 6 & 0.17 & 0.64 & 3.84 & 0.028 \\
\hline Bta13042 & Facilitated glucose transporter member 8 & 0.88 & 2.16 & 2.46 & 0.001 \\
\hline Bta07749 & Facilitated glucose transporter protein 1 & 56.59 & 123.73 & 2.19 & 5.49E-05 \\
\hline Bta11838 & Facilitated glucose transporter protein 1 & 16.4 & 31.56 & 1.92 & 1.89E-04 \\
\hline Bta02871 & Facilitated glucose transporter protein 1 & 11.42 & 21.09 & 1.85 & 2.43E-05 \\
\hline Bta08290 & Facilitated glucose transporter member 8 & 3.85 & 6.15 & 1.6 & 0.028 \\
\hline Bta08091 & Facilitated glucose transporter member 8 & 4.87 & 2.71 & 0.56 & 0.038 \\
\hline Bta01207 & Facilitated glucose transporter member 1 & 50.02 & 31.05 & 0.62 & 0.027 \\
\hline Gene ID & Gene name & VF72 & ToCV72 & FC & adjusted $\mathrm{p}$ \\
\hline Bta11838 & Facilitated glucose transporter protein 1 & 13.84 & 35.04 & 2.53 & 4.36E-04 \\
\hline Bta07749 & Facilitated glucose transporter protein 1 & 42.32 & 99.55 & 2.35 & $9.46 \mathrm{E}-04$ \\
\hline Bta06616 & Facilitated glucose transporter protein 1 & 7.24 & 14.62 & 2.02 & 0.002 \\
\hline Bta12976 & Facilitated glucose transporter member 8 & 8.28 & 3.99 & 0.48 & 1.77E-04 \\
\hline \multicolumn{6}{|c|}{ b) a-glucosidase genes } \\
\hline Gene ID & Gene name & VF24 & ToCV24 & FC & adjusted $\mathrm{p}$ \\
\hline Bta11979 & a-glucosidase & 389.02 & 723.51 & 1.86 & 7.45E-10 \\
\hline Bta11975 & a-glucosidase & 102.83 & 183.64 & 1.79 & $6.89 \mathrm{E}-05$ \\
\hline Bta12678 & a-glucosidase & 42.64 & 75.44 & 1.77 & $2.85 \mathrm{E}-07$ \\
\hline Bta11977 & a-glucosidase & 6.57 & 11.47 & 1.74 & 1.07E-05 \\
\hline Bta03818 & a-glucosidase & 32.07 & 53.18 & 1.66 & 0.018 \\
\hline Bta12683 & a-glucosidase & 37.12 & 60.72 & 1.64 & $1.99 \mathrm{E}-05$ \\
\hline Bta14419 & a-glucosidase & 5.55 & 8.88 & 1.6 & 0.016 \\
\hline Bta11978 & a-glucosidase & 35.58 & 53.79 & 1.51 & 2.87E-04 \\
\hline Bta03992 & a-glucosidase & 9.74 & 4.18 & 0.43 & $1.67 \mathrm{E}-04$ \\
\hline Bta14422 & a-glucosidase & 25.12 & 11.31 & 0.45 & $1.90 \mathrm{E}-05$ \\
\hline Bta04306 & a-glucosidase & 24.19 & 14.88 & 0.62 & 0.021 \\
\hline Bta05396 & a-glucosidase & 32.38 & 21.1 & 0.65 & 0.047 \\
\hline Gene ID & Gene name & VF48 & ToCV48 & FC & adjusted $p$ \\
\hline Bta05340 & a-glucosidase & 3.64 & 9.61 & 2.64 & 0.049 \\
\hline Bta14313 & 1,4-alpha-glucan branching enzyme GlgB & 8.7 & 2.17 & 0.25 & 0.002 \\
\hline Bta14422 & a-glucosidase & 31.68 & 15.53 & 0.49 & 0.01 \\
\hline Gene ID & Gene name & VF72 & ToCV72 & FC & adjusted $\mathrm{p}$ \\
\hline Bta05340 & a-glucosidase & 3.64 & 9.61 & 2.64 & 0.049 \\
\hline Bta14422 & a-glucosidase & 18.14 & 5.85 & 0.32 & $1.12 \mathrm{E}-05$ \\
\hline Bta12682 & a-glucosidase & 13.78 & 6.12 & 0.44 & 2.17E-05 \\
\hline \multicolumn{6}{|c|}{ c) Uric acid pathway genes } \\
\hline Gene ID & Gene name & VF24 & ToCV24 & FC & adjusted $\mathrm{p}$ \\
\hline Bta14011 & OHCU-decarboxylase & 29.1 & 48.96 & 1.68 & 0.038 \\
\hline Gene ID & Gene name & VF48 & ToCV48 & FC & adjusted $p$ \\
\hline Bta14011 & OHCU-decarboxylase & 19.14 & 45.44 & 2.37 & 0.043 \\
\hline
\end{tabular}


Table 2 Genes encoding glucose transporters (a), a-glucosidases (b), and that are associated with the uric acid pathway (c) showing significant expression differences between whiteflies fed on ToCV-infected and uninfected tomato leaves for 24, 48, or $72 \mathrm{~h}$ (Continued)

\begin{tabular}{clllll}
\hline Gene ID & Gene name & VF72 & ToCV72 & FC & adjusted p \\
Bta15430 & Uricase & 4.19 & 14.18 & 3.39 & $8.71 \mathrm{E}-04$ \\
Bta14011 & OHCU-decarboxylase & 24.55 & 78.78 & 3.21 & $3.43 \mathrm{E}-05$ \\
Bta09595 & phosphoribosylformylglycinaminde cyclo-ligase & 11.42 & 24.83 & 2.17 & $8.36 \mathrm{E}-04$ \\
\hline
\end{tabular}

Differentially expressed genes were selected based on criteria of FC $\geq 1.5$ for up-regulated genes or $\leq 0.67$ for down-regulated genes with FDR $<0.05$ estimated with edgeR

${ }^{\mathrm{a}}$ FPKM values from virus-free (VF) whiteflies fed on uninfected tomatoes for periods of 24,48 , or $72 \mathrm{~h}$

${ }^{b}$ FPKM values from whiteflies fed on ToCV-infected tomatoes (ToCV) for periods of 24,48 , or $72 \mathrm{~h}$

'Fold change (FC) values from ToCV vs. virus-free whiteflies

Table 3 Up-regulated genes in whitefly (B. tabaci MEAM1) in response to feeding on ToCV-infected vs. uninfected tomato for 24, 48, and $72 \mathrm{~h}$

\begin{tabular}{|c|c|c|c|c|c|c|}
\hline & Gene ID & Annotation & $V^{a}$ & $\mathrm{ToCV}^{\mathrm{b}}$ & $\mathrm{FC}^{\mathrm{C}}$ & adjusted $\mathrm{p}$ \\
\hline \multirow[t]{10}{*}{ a) $24 \mathrm{~h}$} & Bta13784 & Unknown protein & 4.32 & 16.4 & 3.8 & 0.000138689 \\
\hline & Bta14319 & Unknown protein & 4.75 & 17.25 & 3.63 & 1.19E-05 \\
\hline & Bta12989 & Unknown protein & 8.19 & 26.88 & 3.28 & 2.62E-09 \\
\hline & Bta02212 & FLYWCH and MULE domain containing protein & 3.5 & 11.19 & 3.2 & 0.000106094 \\
\hline & Bta10158 & Unknown protein & 7.87 & 22.33 & 2.84 & $3.27 \mathrm{E}-06$ \\
\hline & Bta03426 & Unknown protein & 7.05 & 18.87 & 2.68 & $3.88 \mathrm{E}-06$ \\
\hline & Bta12743 & Unknown protein & 4.12 & 11.03 & 2.67 & 1.59E-06 \\
\hline & Bta08587 & Unknown protein & 75.18 & 200.93 & 2.67 & $2.82 \mathrm{E}-11$ \\
\hline & Bta06140 & Unknown protein & 5.29 & 13.75 & 2.6 & 3.07E-06 \\
\hline & Bta00711 & Unknown protein & 5.27 & 13.56 & 2.57 & 0.000111824 \\
\hline \multirow[t]{2}{*}{ b) $48 \mathrm{~h}$} & Bta14011 & 2-oxo-4-hydroxy-4-carboxy-5-ureidoimidazoline decarboxylase & 19.14 & 45.44 & 2.37 & 0.043929335 \\
\hline & Bta12531 & Unknown protein & 682.9 & 1411.26 & 2.07 & 0.049555196 \\
\hline \multirow[t]{16}{*}{ c) $72 \mathrm{~h}$} & Bta15430 & Uricase & 4.19 & 14.18 & 3.39 & 0.000871375 \\
\hline & Bta14011 & 2-oxo-4-hydroxy-4-carboxy-5-ureidoimidazoline decarboxylase & 24.55 & 78.78 & 3.21 & 3.43E-05 \\
\hline & Bta02847 & Sulfotransferase & 13.64 & 41.95 & 3.08 & 0.003309401 \\
\hline & Bta05740 & Unknown protein & 19.32 & 50.46 & 2.61 & 5.07E-05 \\
\hline & Bta05340 & a-glucosidase & 3.95 & 10.03 & 2.54 & 0.014904518 \\
\hline & Bta11838 & Facilitated glucose transporter protein 1 & 13.84 & 35.04 & 2.53 & 0.000436429 \\
\hline & Bta00960 & Unknown protein & 10.72 & 26.79 & 2.5 & 5.83E-05 \\
\hline & Bta07749 & Facilitated glucose transporter protein 1 & 42.32 & 99.55 & 2.35 & 0.000946084 \\
\hline & Bta08287 & Unknown protein & 4.5 & 10.11 & 2.25 & 2.85E-06 \\
\hline & Bta09733 & AGAP011571-PA & 5.8 & 12.92 & 2.23 & 0.009044855 \\
\hline & Bta03426 & Unknown protein & 6.31 & 13.72 & 2.18 & 0.010482148 \\
\hline & Bta09595 & Phosphoribosylformylglycinamidine cyclo-ligase & 11.42 & 24.83 & 2.17 & 0.000835974 \\
\hline & Bta09412 & Protein FAM134C & 8.47 & 18.01 & 2.13 & 0.003854887 \\
\hline & Bta04103 & Patatin-like phospholipase domain-containing protein 2 & 14.04 & 29.37 & 2.09 & 0.001241884 \\
\hline & Bta00373 & Calcium-independent phospholipase A2-gamma & 21.36 & 43.86 & 2.05 & 0.022562539 \\
\hline & Bta06616 & Facilitated glucose transporter protein 1 & 7.24 & 14.62 & 2.02 & 0.001862466 \\
\hline
\end{tabular}

Differentially expressed genes were selected based on criteria of FPKM $>10$ with FC $\geq 2$ and adjusted $p$-value $<0.05$ with edgeR

${ }^{a}$ FPKM values from virus-free (VF) whiteflies

${ }^{\mathrm{b}} \mathrm{FPKM}$ values from ToCV whiteflies

'Fold change (FC) for ToCV vs. virus-free (VF) whiteflies. The top 10 genes out of a total of 259 at $24 \mathrm{~h}$ are listed, whereas at $48 \mathrm{~h}$ and $72 \mathrm{~h}$ all differentially regulated genes are shown in the table 
Table 4 Down-regulated genes in whitefly (B. tabaci MEAM1) in response to feeding on ToCV-infected vs. uninfected tomato for 24, 48 , and $72 \mathrm{~h}$

\begin{tabular}{|c|c|c|c|c|c|c|}
\hline & Gene ID & Annotation & $V F^{a}$ & $\mathrm{ToCV}^{\mathrm{b}}$ & $\mathrm{FC}^{\mathrm{C}}$ & adjusted $\mathrm{p}$ \\
\hline \multirow[t]{10}{*}{ a) $24 \mathrm{~h}$} & Bta15563 & Vitellogenin-B & 21.82 & 3.19 & 0.15 & $6.12 \mathrm{E}-10$ \\
\hline & Bta13640 & Chemosensory protein & 354.23 & 60.58 & 0.17 & $1.13 \mathrm{E}-09$ \\
\hline & Bta08821 & Glycerol-3-phosphate dehydrogenase & 35.65 & 7.71 & 0.22 & $5.56 \mathrm{E}-09$ \\
\hline & Bta07380 & Unknown protein & 14.65 & 3.65 & 0.25 & 0.00598194 \\
\hline & Bta13457 & Thiol-activated cytolysin & 61.35 & 15.63 & 0.25 & $1.12 \mathrm{E}-10$ \\
\hline & Bta02903 & Heat shock protein 70 & 60.16 & 15.82 & 0.26 & $8.81 \mathrm{E}-07$ \\
\hline & Bta13864 & Unknown protein & 101.64 & 28.08 & 0.28 & 3.07E-11 \\
\hline & Bta15275 & Unknown protein & 46.31 & 14 & 0.3 & 0.000637335 \\
\hline & Bta07359 & Transcription elongation factor B polypeptide 2 & 26.65 & 8.45 & 0.32 & 5.77E-07 \\
\hline & Bta07162 & DDB1-and CUL4-associated factor & 25.98 & 8.5 & 0.33 & $1.39 \mathrm{E}-05$ \\
\hline \multirow[t]{3}{*}{ b) $48 \mathrm{~h}$} & Bta13864 & Gamma crystallin & 202.49 & 29.99 & 0.15 & 0.019515766 \\
\hline & Bta14312 & Sucrase & 15.11 & 4.19 & 0.28 & $6.52 \mathrm{E}-07$ \\
\hline & Bta14422 & a-glucosidase & 31.68 & 15.53 & 0.49 & 0.010355562 \\
\hline \multirow[t]{10}{*}{ c) $72 \mathrm{~h}$} & Bta11097 & Unknown protein & 19.92 & 4.93 & 0.25 & 5.07E-05 \\
\hline & Bta07084 & Unknown protein & 21.71 & 5.56 & 0.26 & $5.78 \mathrm{E}-09$ \\
\hline & Bta14126 & Unknown protein & 206.82 & 56.75 & 0.27 & $2.69 \mathrm{E}-08$ \\
\hline & Bta14115 & Unknown protein & 57.59 & 15.36 & 0.27 & $5.22 \mathrm{E}-08$ \\
\hline & Bta00788 & Unknown protein & 361.81 & 101.82 & 0.28 & $2.32 \mathrm{E}-13$ \\
\hline & Bta00782 & Unknown protein & 24.25 & 6.88 & 0.28 & $1.12 \mathrm{E}-05$ \\
\hline & Bta14116 & Unknown protein & 183.75 & 53.65 & 0.29 & $2.09 \mathrm{E}-10$ \\
\hline & Bta00784 & Unknown protein & 114.92 & 35.01 & 0.3 & $2.32 \mathrm{E}-13$ \\
\hline & Bta00783 & Unknown protein & 20.69 & 6.28 & 0.3 & $4.18 \mathrm{E}-06$ \\
\hline & Bta14422 & a-glucosidase & 18.14 & 5.85 & 0.32 & $1.12 \mathrm{E}-05$ \\
\hline
\end{tabular}

Differentially expressed genes were selected based on criteria of FPKM $>10$ with $\mathrm{FC} \leq 0.5$ and adjusted $p$-value $<0.05$ with edgeR

${ }^{\mathrm{a} F P K M}$ values from virus-free (VF) whiteflies

${ }^{\mathrm{b}} \mathrm{FPKM}$ values from ToCV whiteflies

${ }^{C}$ Fold change (FC) for ToCV vs. virus-free (VF) whiteflies. Only the top 10 genes out of total of 271 genes downregulated at $24 \mathrm{~h}$, and of 110 genes down-regulated at $72 \mathrm{~h}$, respectively are shown in the table; whereas at $48 \mathrm{~h}$ all differentially regulated genes are shown in the table

crystallin, $\mathrm{FC}=0.15, p$-value $=0.0195) ;$ Bta14312 (sucrose, $\mathrm{FC}=0.28, p$-value $=6.52 \mathrm{E}-07)$; and Bta14422 ( $\alpha$-glucosidase, $\mathrm{FC}=0.49, p$-value $=0.01$ ). A total of 110 genes were identified as down-regulated from the whiteflies provided with $72 \mathrm{~h}$ AAP on ToCV-infected tomatoes compared to whiteflies fed on uninfected plants using stringent criteria. A large number of down-regulated orphan genes (74 out of 160) were also identified. Interestingly, seven of the 10 most down-regulated genes in ToCV whiteflies with $72 \mathrm{~h}$ AAP were present as clusters on two scaffolds with significant similarity to one another at the nucleotide level [24].

\section{KEGG pathways analysis}

KEGG (Kyoto Encyclopedia of Genes and Genomes) pathway analysis was performed on DEGs revealed by the RNA-Seq experiments to identify potential pathways up-and down-regulated in whiteflies fed on ToCVinfected tomato at each of the three time points. Only $20.6 \%$ (92 out of 447) of the total genes up-regulated in
ToCV whiteflies at $24 \mathrm{~h}$ were able to be annotated using KEGG [35]. Figure 2a provides a representation of the global functionality of the genes and summarizes the molecular pathways identified from up-regulated genes in ToCV whiteflies at $24 \mathrm{~h}$. The five categories of pathways most represented as up-regulated in whiteflies fed on ToCV-infected tomato for $24 \mathrm{~h}$ were 1 ) metabolic pathways, 2) transport and catabolism, 3) cell growth and death categories, 4) endocrine system pathways, and 5) immune system pathways. $50.2 \%$ (272 out of 542) of the significantly differentially expressed down-regulated genes were annotated to KEGG pathways at $24 \mathrm{~h}$ for ToCV whiteflies, with the five most represented pathway categories identified as associated with: 1) signal transduction, 2) cancer, 3) the endocrine system, 4) protein folding, sorting, and degradation, and 5) metabolic pathways (Fig. 2b). KEGG analysis was not performed for the $48 \mathrm{~h}$ AAP because only 11 DEGs were present in ToCV whiteflies at $48 \mathrm{~h}$. 


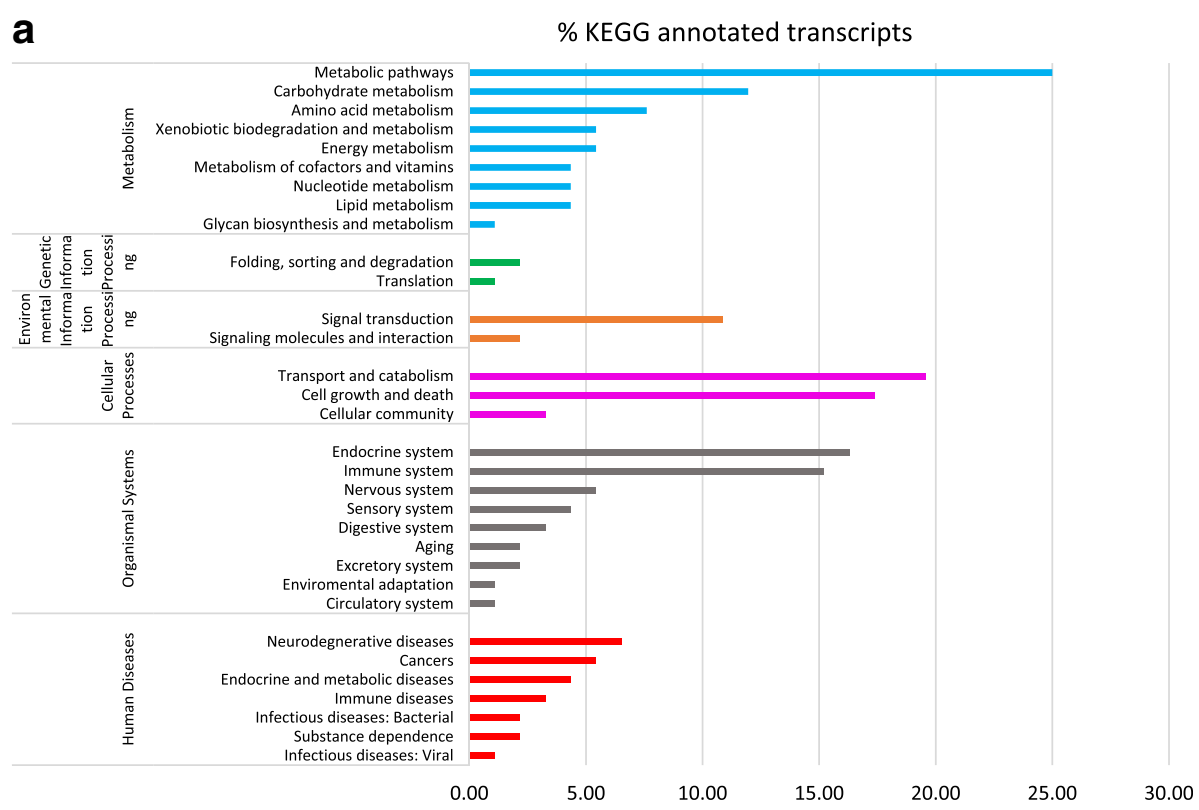

b

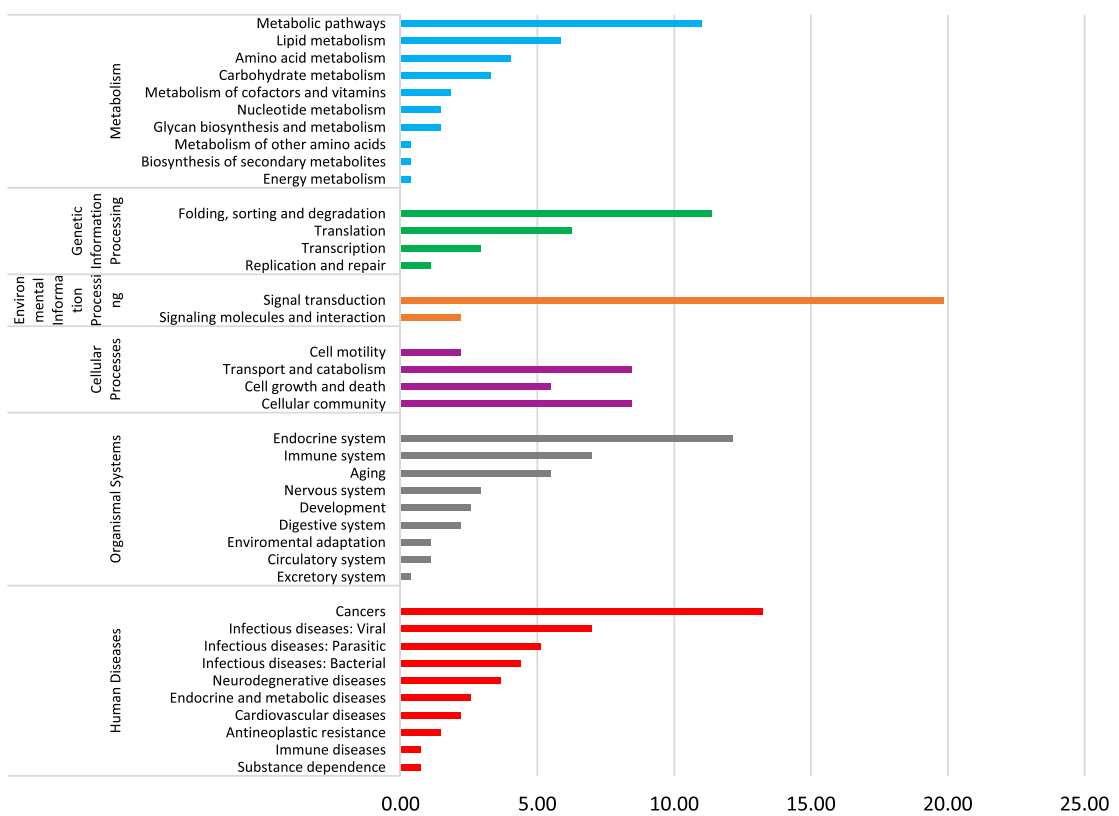

Fig. 2 Summary of the KEGG reference pathways associated with up-regulated (a) and down-regulated genes (b) from whiteflies fed on ToCV-infected tomato (ToCV whiteflies) for $24 \mathrm{~h}$. Bars represent the percentage of the total KEGG annotated transcripts (92 genes out of a total of 447 up-regulated genes and 272 genes out of a total of 542 down-regulated genes) in the ToCV whiteflies at $24 \mathrm{~h}$ compared to virus-free whiteflies

At $72 \mathrm{~h}, 48 \%$ (24 out of 50 ) of the significantly upregulated and $27 \%$ (43 out of 160 ) of the down-regulated genes from ToCV whiteflies were annotated using KEGG. Only the three most represented KEGG pathway categories will be discussed for ToCV whiteflies with the $72 \mathrm{~h}$ AAP because only a few genes were assigned to the fourth and fifth categories. The three categories of pathways most represented were metabolic pathways, nucleotide metabolism, and signal transduction among up-regulated genes in
ToCV whiteflies at $72 \mathrm{~h}$ compared to VF whiteflies (Fig. 3a). In contrast, genes associated with transport and catabolism, metabolic pathways, and the endocrine system were the most prevalent categories of pathways identified from down-regulated genes in ToCV whiteflies at $72 \mathrm{~h}$ compared to VF whiteflies (Fig. 3b). Detailed information about the genes, KO (KEGG orthology), annotations, score, and full pathways related to metabolism, genetic information processing, environmental information processing, 
a

$\%$ of KEGG annotated transcripts

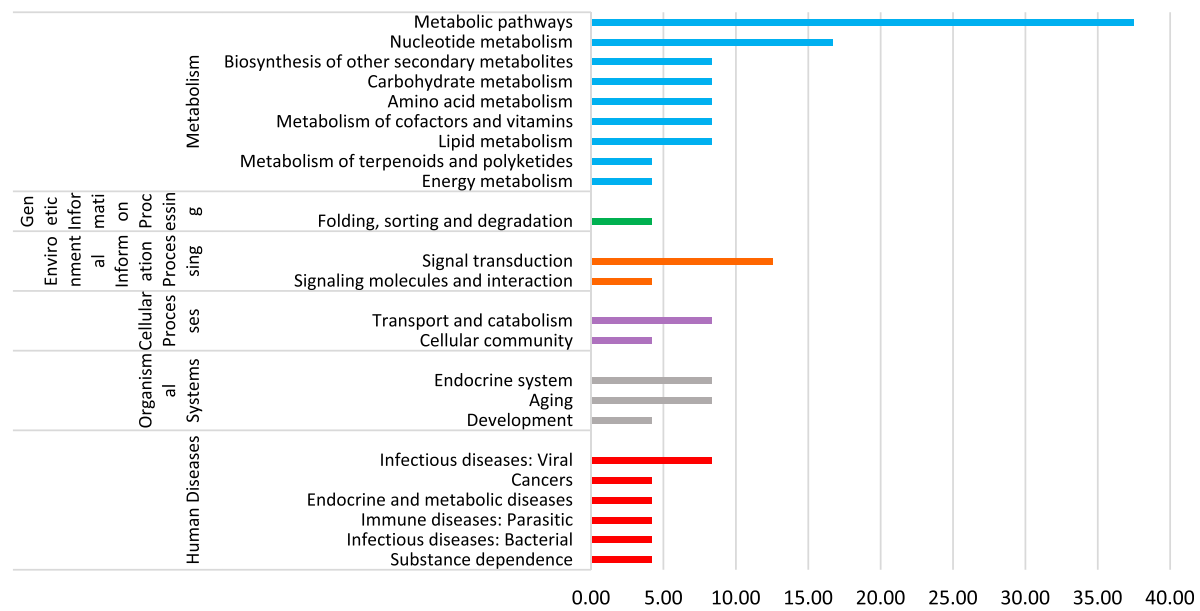

b

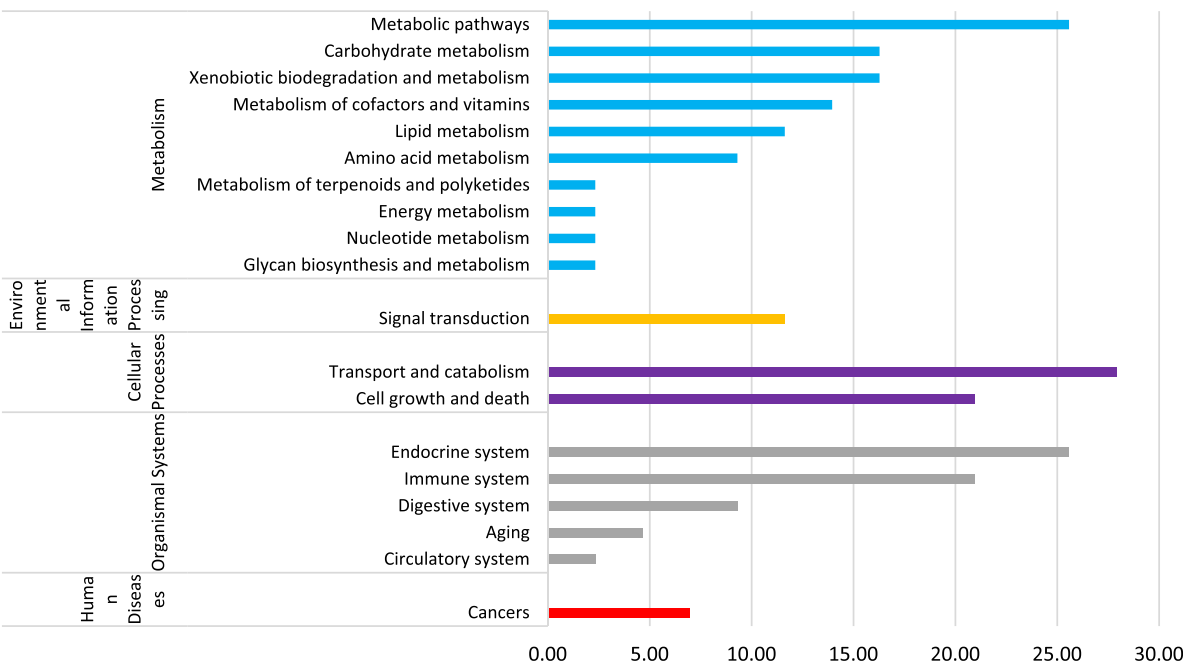

Fig. 3 Summary of the KEGG reference pathways associated with up-regulated (a) and down-regulated genes (b) from whiteflies fed on ToCV-infected tomato (ToCV whiteflies) for $72 \mathrm{~h}$. Bars represent the percentage of the total KEGG annotated transcripts (24 genes out of a total of 50 up-regulated genes and 43 genes out of a total of 160 down-regulated genes) in the ToCV whiteflies at $72 \mathrm{~h}$ compared to virus-free whiteflies

cellular processes, organismal systems, and human diseases is available from ToCV and VF whiteflies at 24 and $72 \mathrm{~h}$ in Additional files 4 and 5.

Further analysis of KEGG data revealed eight differentially expressed receptor genes (two up-regulated: neuroactive ligand \& cell adhesion and six down-regulated: extra cellular matrix) found in ToCV whiteflies after $24 \mathrm{~h}$ AAP compared with only one cytokine-cytokine receptor up-regulated at $72 \mathrm{~h}$ (Table 5). Interestingly, 64 genes (10 up-regulated and 54 down-regulated) from signal transduction pathways were differentially regulated in ToCV whiteflies at $24 \mathrm{~h}$ compared with only eight (three up-regulated and five down-regulated) at $72 \mathrm{~h}$ (Additional file 6). Higher expression of genes with functions associated with endocytosis (one gene), phagosomes (two genes), lysosomes (13 genes), and peroxisomes (two genes) were found in whiteflies given a $24 \mathrm{~h}$ AAP. In contrast, down-regulation of a different set of genes (with the exception of two genes, Bta08035 \& Bta03882 that showed a reversed expression pattern compared to their expression at $24 \mathrm{~h}$ ) that belonged to only two categories (11 lysosome genes and one peroxisome gene) were found in ToCV whiteflies after the $72 \mathrm{~h}$ AAP (Table 6). Immune system related pathways were also highly represented in ToCV whiteflies given a $24 \mathrm{~h}$ AAP compared with VF whiteflies. A total of 33 immunity genes (14 up-regulated and 19 down-regulated) from 11 distinct immunity pathways were differentially regulated in ToCV whiteflies following the $24 \mathrm{~h} \mathrm{AAP}$, whereas nine genes from a single immunity pathway showed reduced expression in ToCV whiteflies after the $72 \mathrm{~h}$ compared with those in VF whiteflies. Among the 11 immunity pathways, the most highly 
Table 5 Differential regulation of receptor genes associated with signaling molecules and interaction pathways in ToCV whiteflies compared to virus-free (VF) whiteflies after feeding periods of $24 \mathrm{~h}$ or $72 \mathrm{~h}$

\begin{tabular}{lllll}
\hline Time point & Signaling molecules and interaction & Gene ID & Annotation & FC (ToCVNF) \\
\hline $\begin{array}{llll}24 \mathrm{~h} \\
\text { up-regulated genes }\end{array}$ & Neuroactive-ligand receptor interaction & Bta11339 & Nicotinic acetylcholine receptor subunit alpha 6 & 1.83 \\
& Cell adhesion molecules & Bta04342 & Neural cell adhesion molecule 1-B & 1.52 \\
$24 \mathrm{~h}$ & ECM-receptor interaction & Bta12425 & Laminin subunit gamma-1 & 0.15 \\
down-regulated genes & & Bta12426 & Laminin subunit gamma-1 & 0.38 \\
& & Bta09051 & Laminin subunit beta-1 & 0.57 \\
& & Bta10097 & Laminin subunit alpha-1 & 0.38 \\
$72 \mathrm{~h}$ & Bta07723 & CG10625, isoform H & 0.61 \\
up-regulated genes & Cytokine-cytokine receptor interaction & Bta04818 & Type I serine/threonine kinase receptor &
\end{tabular}

represented category from ToCV whiteflies was that of antigen processing and presentation (Additional file 7). All of the 12 up-regulated genes from "antigen processing and presentation" pathways were annotated as "cathepsin B", while all down-regulated genes in ToCV whiteflies at $24 \mathrm{~h}$ from the same immunity pathway were identified as $70 \mathrm{kDa}$ heat shock proteins except one, Bta09211 (Calnexin) (Additional file 7). At $72 \mathrm{~h}$, again a different set of six cathepsin B genes were down-regulated in ToCV whiteflies, with the exception of two cathepsin B genes (Bta03882 and Bta08035) that showed reverse expression pattern in ToCV whiteflies at $72 \mathrm{~h}$ compared to $24 \mathrm{~h}$.

Notably, genes associated with infectious viral diseases in other organisms were also highly represented under the "human diseases" category among down-regulated genes in ToCV whiteflies at $24 \mathrm{~h}$. Nineteen genes that have been implicated in human viral diseases exhibited reduced expression in whiteflies upon feeding on ToCV-infected

Table 6 Transport and catabolism genes significantly up- and down-regulated in whiteflies given feeding periods of $24 \mathrm{~h}$ and $72 \mathrm{~h}$ on ToCV-infected tomato compared to whiteflies fed on uninfected tomato

\begin{tabular}{|c|c|c|c|c|c|}
\hline \multirow[t]{2}{*}{ Category } & \multicolumn{3}{|c|}{ ToCV24 whiteflies (18 up-regulated genes) } & \multicolumn{2}{|c|}{ ToCV72 whiteflies (12 down-regulated genes) } \\
\hline & Gene ID & Annotation & $\mathrm{FC}^{\mathrm{a}}$ & Gene ID & Annotation \\
\hline Endocytosis & Bta08332 & Arrestin 1c & 1.71 & None & \\
\hline \multirow[t]{2}{*}{ Phagosome } & Bta09524 & V-type proton ATPase subunit E & 6.68 & None & \\
\hline & Bta00642 & V-type proton ATPase subunit E2 & 3.84 & & \\
\hline \multirow[t]{13}{*}{ Lysosome } & Bta10546 & Cathepsin B & 2.81 & Bta12605 & Cathepsin B \\
\hline & Bta02553 & Cathepsin B & 2.47 & Bta12604 & Cathepsin B \\
\hline & Bta07402 & Cathepsin B & 2.12 & Bta03885 & Cathepsin B \\
\hline & Bta08035 & Cathepsin B & 2.09 & Bta03880 & Cathepsin B \\
\hline & Bta01772 & Cathepsin B & 2.09 & Bta03882 ${ }^{b}$ & Cathepsin B \\
\hline & Bta01771 & Cathepsin B & 2.05 & Bta08035 & Cathepsin B \\
\hline & Bta03883 & Cathepsin B & 1.97 & Bta09314 & Cathepsin B \\
\hline & Bta10291 & Cathepsin B & 1.82 & Bta14721 & Cathepsin B \\
\hline & Bta11419 & Cathepsin B & 1.76 & Bta13075 & Legumain \\
\hline & Bta01769 & Cathepsin B & 1.73 & Bta04870 & Cathepsin F \\
\hline & Bta03882 & Cathepsin B & 1.68 & Bta07355 & $\begin{array}{l}\mathrm{N}(4) \\
\text {-(Beta-N-acetylglucosaminyl)-L-asparaginase }\end{array}$ \\
\hline & Bta11420 & Cathepsin B & 1.56 & & \\
\hline & Bta07114 & Cathepsin F & 1.86 & & \\
\hline \multirow[t]{2}{*}{ Peroxisome } & Bta08493 & Catalase & 2.06 & Bta13675 & Fatty acyl-CoA reductase 1 \\
\hline & Bta11280 & Superoxide dismutase [Cu-Zn] & 1.93 & & \\
\hline
\end{tabular}

${ }^{\mathrm{a}} \mathrm{FC}$, fold change values of whiteflies fed on ToCV-infected tomato vs. whiteflies fed on uninfected tomato with adjusted $p$-values $(<0.05)$

${ }^{\mathrm{b}}$ Genes showing opposite expression patterns in whiteflies after feeding periods of $24 \mathrm{vs} .72 \mathrm{~h}$ 
tomato after the $24 \mathrm{~h}$ AAP compared to those that fed on uninfected tomato. By contrast, only one (Bta04024, $W n t, \mathrm{FC}=1.65, p$-value $=0.004)$ and two genes $(B t a 06242$, Farnesyl pyrophosphate synthase, $\mathrm{FC}=1.7, p$-value $=0.011$ and Bta04818, Type I serine/threonine kinase receptor, $\mathrm{FC}=1.79, p$-value $=0.002)$ implicated in human viral diseases were up-regulated in ToCV whiteflies following $24 \mathrm{~h}$ and $72 \mathrm{~h}$ AAPs, respectively.

\section{RT-qPCR validation of select DEGs}

An RT-qPCR experiment was performed on eight DEGs and three non-regulated genes for validation of the gene expression patterns identified using the RNA-Seq data. The eight DEGs selected for RT-qPCR validation were chosen either because their homologs had been previously implicated in viral interactions, or we were interested in the putative roles of these genes in the whitefly response to feeding on ToCV-infected plants. The eight DEGs selected were: Bta14011 (2-oxo-4-hydroxy-4-carboxy-5-ureidoimidazoline decarboxylase), Bta14422 ( $\alpha$-glucosidase), Bta15563 (Vitellogenin-B), Bta13640 (chemosensory protein), Bta07749 (facilitated glucose transporter protein 1), Bta02560 (Cathepsin L-like protease), and two orphan genes: Bta14126 and Bta00788. Three nonregulated genes selected were: Bta06348 (V-type proton ATPase subunit e 2), Bta14921 (Scaffold attachment factor B2), and Bta14141 (Mitogen-activated protein kinase kinase kinase 7). Each of the 11 genes showed the same expression pattern (increased, decreased or unchanged) for both RT-qPCR and RNA-Seq analyses when compared from two different RNA samples generated in two different years, 2014 and 2015 (Fig. 4 \& Additional file 8 ), validating the gene expression data in the RNA-Seq experiments.

\section{Discussion}

Temporal shift in gene expression

We examined for the first time, differences in global gene expression in B. tabaci MEAM1 whiteflies in response to feeding on plants infected with a semipersistently transmitted virus. Gene expression differences were compared between whiteflies feeding on tomato plants (S. lycopersicum $\mathrm{cv}$. Moneymaker) infected with the crinivirus, ToCV, or on uninfected tomato following three different AAPs (24, 48, and $72 \mathrm{~h}$ ). A far greater number of transcriptional changes occurred with AAPs of $24 \mathrm{~h}$ (447 up-regulated, 542 downregulated) and $72 \mathrm{~h}$ (50 up-regulated, 160 down-regulated) in ToCV whiteflies than with the $48 \mathrm{~h} \mathrm{AAP}$ (four upregulated, seven down-regulated), compared with whiteflies fed on uninfected tomato plants (Fig. 1a). These results demonstrated an initial spike with 989 genes differentially expressed between B. tabaci MEAM1 whiteflies fed on ToCV-infected and uninfected tomato at $24 \mathrm{~h}$, indicating that the whiteflies were responding to the presence of ToCV in tomato, changes in the content of tomato sap due to infection by $\mathrm{ToCV}$ or a combination of both. Interestingly, transmission of ToCV by B. tabaci MEAM1 is most efficient during the first $24 \mathrm{~h}$ following virus acquisition (70\% transmission), with rates declining over a 3 day period to $26 \%$ by $48 \mathrm{~h}$ and $5 \%$ by $72 \mathrm{~h}$ if whiteflies are removed from virus-infected source plants [36]. The limited number of significant differences in gene expression

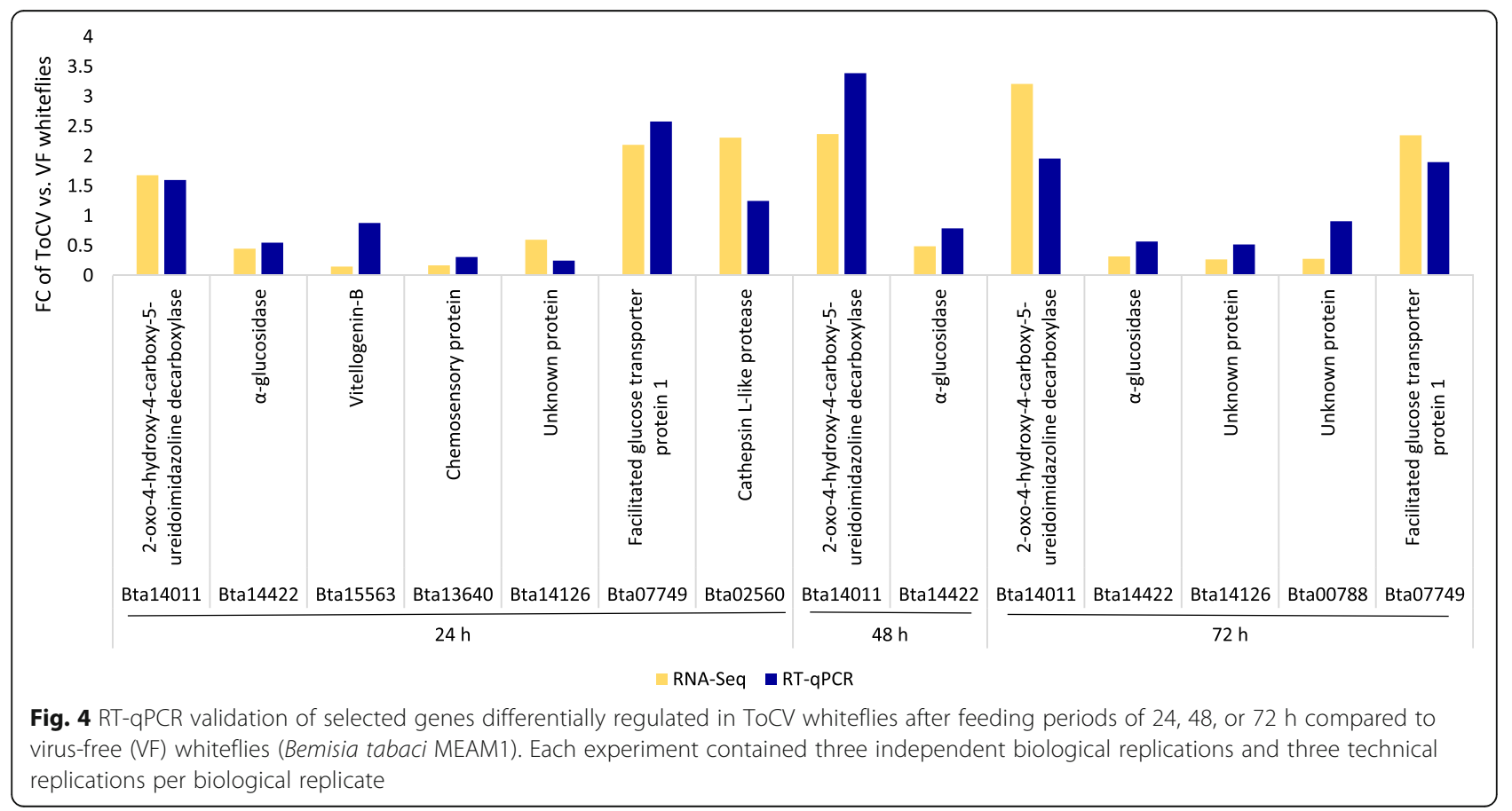


between healthy and ToCV whiteflies after the $48 \mathrm{~h}$ AAP suggests that initial changes in gene expression resulting from the influence of $\mathrm{ToCV}$ in phloem had occurred prior to the 48 sampling, but subsequent changes that became more apparent later were only beginning. The latter was evidenced by the differential expression of OHCUdecarboxylase at both $48 \mathrm{~h}$ and at $72 \mathrm{~h}$ sampling time points. When whiteflies were given an AAP of $72 \mathrm{~h}$, 272 genes were differentially expressed in ToCV whiteflies compared to VF whiteflies, and the majority of these genes were distinct from those exhibiting differential expression at $24 \mathrm{~h}$ (Fig. 1a \& b). The timing of the shift in gene expression at $72 \mathrm{~h}$ coincides with the time at which whiteflies (B. tabaci MEAM1) lose their ability to transmit virus [36]. Although feeding continued through $72 \mathrm{~h}$ in these experiments, the shifts may reflect physiological changes that occur in the vector with passage of time following the initial shift in gene expression that was observed after initiation of feeding. These temporal changes in gene expression may contribute to the loss of virus from retention sites in the anterior foregut of the whitefly vector and loss of virus transmissibility.

\section{Orphan genes}

A significant number of orphan genes (379 out of 1,155) were present among DEGs from ToCV whiteflies compared to VF whiteflies. Orphan genes do not show any detectable sequence similarities to genes in the genomes of other organisms [26]. They constitute a large portion of every sequenced genome, and are common among other arthropods. Over $50 \%$ and $36 \%$ of the genes in the genome of the lone star tick, Amblyomma americanum and water flea, Daphnia pulex, respectively were identified as orphan genes. The genomes of Drosophila melanogaster and Aedes aegypti contain 18.6\% and 27.1\% orphan genes [26, 37, 38]. Expression of orphan genes is often attributed to evolutionary adaptation of insects, host-parasite interactions, and interactions with the environment $[25,26]$. Examples of the role of orphan genes in host-parasite interactions are found in the apicomplexan parasites, Plasmodium and Theileria, in which families of orphan genes encode surface antigens that are involved in interactions between the parasites and their hosts [39]. Orphan genes from $D$. pulex that reside within tandemly duplicated gene clusters are significantly over-represented in transcriptomes generated from exposure to biotic and abiotic factors, as well as in different life stages of the insect [38]. Additionally, their importance is reported in D. melanogaster fitness, and have been shown to be under selection in D. melanogaster and mammals [40,41]. We suspect specific roles for differentially expressed orphan genes in whiteflies associated with feeding on ToCV-infected plants, because: 1) these genes comprise a significantly high proportion of the 1,155 DEGs in ToCV whiteflies compared to VF whiteflies and 2) altered regulation of orphan genes has been found with host-parasite interactions in other arthropods.

Because these orphan genes do not show homology to known proteins from other species, we were interested in their possible origin. Various models for the origin of orphan genes have been proposed: 1) gene duplication, 2) de novo gene evolution from ancestral non-coding DNA, and 3) horizontal gene transfer [25, 26, 42]. In the gene duplication model, new copies of a gene can remain functionally active and identical to the original copy, become a pseudogene, or attain a completely new function through evolution [26]. Orphan genes can also evolve de novo from non-coding regions of genomes by translocation of a DNA segment into a transcriptionally active location controlled by regulatory elements. Such orphan genes often encode short secreted proteins ( 100 amino acids in length) [26]. The identification of orphan gene homology in the non-transcribed regions of a sister taxon or in closely related species is necessary to determine if the orphan gene evolved de novo from noncoding regions [25]. The eight orphan genes present as a tandem cluster on scaffold 17 in the whitefly genome [24] also showed high levels of homology with nontranscribed regions of the genome, and encode small peptides ranging from 88 to 132 amino acids in length (Table 1). The presence and pattern of sequences on non-transcribed regions of the genome with homology to either the full-length Bta04889 sequence or to the 3' end of this gene indicates a possible acquisition and integration of a gene from an unknown microorganism through HGT into the whitefly genome. This may have happened millions of years ago, followed by gene duplication and integration of the acquired gene into a transcribed genomic location that came under control of regulatory sequences. It seems that once Bta04889 or other homologs present on scaffold 17 had been positively selected in the whitefly, possibly through environmental or ecological pressure, further gene duplication occurred, resulting in six additional copies of Bta04889 in the whitefly genome. It is possible that all eight of the differentially down-regulated genes present on scaffold 17 in ToCV whiteflies may have evolved through gene duplication. In support of this, no homologous or nontranscribed sequences were found in the pea aphid genome, which is a sister taxon to whitefly. One possible mechanism inducing down-regulation could be the triggering of the RNAi silencing pathway in the whitefly, because the complex structure of these genes on scaffold 17 is composed of direct and inverted repeats, which may lead to the formation of dsRNA, and generation of siRNAs through the RNAi pathway in ToCV whiteflies; however, further studies are needed. 
The putative origin mechanism of another orphan gene, Bta00788 was also investigated. Bta00788 is among the 21 orphan genes present as a tandem cluster on the scaffold 1103 (Additional file 3a). Six partial homologs of Bta00788 were identified in non-transcribed regions of the whitefly genome present on two different scaffolds (Additional file 3b). Scaffold 1103 contained three nonfunctional full-length copies (99\% identity) and a region corresponding to the $3^{\prime}$ end of Bta00788 (84\% similarity) that was adjacent to a functional copy of Bta00788. This implies Bta00788 may also have originated through gene duplication, thus supporting the model for orphan gene evolution proposed by Domazet-Loso T and Tautz D [43]. In ants, $24-32 \%$ of all orphan genes are located in clusters, with cluster size varying from 2 to 8 genes, although these clusters contained unrelated genes [42]. The orphan gene, Bta04337, was up-regulated in ToCV whiteflies at $24 \mathrm{~h}$ AAP with high FC and FPKM values. The BLAST analysis of Bta04337 revealed two genomic hits, first on a nontranscribed region (99\% identity) present $\sim 7 \mathrm{~kb}$ upstream of Bta04337 and a second genomic hit showed strong homologies to the exons of another up-regulated orphan gene, Bta02258 in ToCV whiteflies at $24 \mathrm{~h}$. It is intriguing that this non-transcribed genomic hit is $99 \%$ identical at the nucleotide level to Bta04337 but it is not a functional copy. One of the possible origins of Bta04337 could be translocation of this non-functional DNA segment into a transcriptionally active region of the genome [26]. Comparative sequence analysis of the $1 \mathrm{~kb}$ promoter region of $B t a 04337$ with a $1 \mathrm{~kb}$ region upstream of the non-functional copy of Bta04337 present on the nontranscribed region revealed significant disparities at nucleotide level. This suggests Bta04337 may have been duplicated and translocated to a region controlled by the regulatory elements of a strong promoter that drives the abundant expression of Bta04337. Interestingly, a second genomic hit for Bta04337 showed strong homology (79-89\%) to the coding sequence of another orphan gene, Bta02258 that has seven introns. It appears that Bta02258 evolved from a parent orphan gene, Bta04337 following intronification. This has also been reported previously for de novo originated orphan genes in the human pathogen, Plasmodium vivax [44]. The significant regulation of orphan genes in B. tabaci in response to ToCV infection of host plants hints at the possible evolution of adaptive mechanisms in the whitefly in response to the crinivirus, ToCV.

\section{Glucose transporters and a-glucosidases}

Higher numbers of facilitated glucose transporter genes were regulated in $\mathrm{ToCV}$ whiteflies with $24 \mathrm{~h}$ than with $72 \mathrm{~h}$ AAPs (Table 2). Interestingly previous studies found that glucose transporter proteins are known to interact with viruses (white spot syndrome virus and feline leukemia virus
C) and induction of the GLUT3 gene and protein in $\mathrm{Hu}$ man immunodeficiency virus (HIV)-infected cells was accompanied by an increase in glucose transport [45-47]. Infection by viruses has been argued to lead to increased metabolic demands upon the host cell and thus a need for increased movement of glucose. Infection of human fibroblasts with Human cytomegalovirus (HCMV), a herpesvirus, also leads to increased glucose consumption, consequently increasing the level of GLUT4 [48]. HIV infection of H9 lymphocytic cells significantly increased GLUT3 gene expression, and this was accompanied by an increase in glucose transport within the infected cells [47]. Although whiteflies do not become infected by ToCV, differential expression of glucose transporter genes in response to virus infection of host plants provides solid evidence for the involvement of these genes in virus-vector interactions important for virus acquisition, retention, or transmission. At a minimum these results demonstrate that feeding on ToCV-infected plants triggers increased expression of glucose transporters, which likely contribute to the virus-whitefly interactions associated with virus transmission.

Besides glucose transporters, another major gene class that showed significantly altered regulation in ToCV whiteflies compared to VF whiteflies was the $\alpha$ glucosidase family. Higher regulation of $\alpha$-glucosidases occurred in ToCV whiteflies with 24 h AAP (12 genes) than with the $48 \mathrm{~h}$ (three genes) and $72 \mathrm{~h}$ (three genes) AAPs (Table 2). Interestingly, Bta14422 ( $\alpha$-glucosidase) was downregulated at all three time points in ToCV whiteflies as demonstrated with RNA-Seq and RT-qPCR performed on RNA generated from independent experiments (Fig. 4). The biological functions of glycosyl hydrolases intervene in many critical steps of life, including catalytic activity, hydrolysis of polysaccharides, and pathogen defense, in addition to the turnover of cell surface carbohydrates [49]. Inhibitors of $\alpha$-glucosidases have been shown to act as antiviral agents against HIV and Hepatitis $B$ virus (HBV) by inducing misfolding of the virus-encoded glycoproteins present in the virus envelope [50, 51]. The fact, that the expression of $\alpha$ glucosidase genes was significantly altered in whiteflies fed on ToCV-infected tomato compared to those fed on uninfected tomato at all three time points, suggests that these genes may also influence factors involved in ToCV interactions with $B$. tabaci, even though ToCV virions do not have a glycoprotein envelope.

\section{Most abundant DEGs with high FPKM and FC values}

When analyzed using more stringent criteria to filter genes with high expression and greater FPKM values that might play critical roles in ToCV and whitefly interactions, all of the ten most up-regulated genes in ToCV whiteflies at $24 \mathrm{~h}$ were classified as unknown (orphan) 
genes, with the exception of the fourth gene, Bta02212, the FLYWCH and MULE domain containing protein. The FLYWCH zinc finger domain containing transcription factor was first characterized in Drosophila and is a modifier of mdg4 proteins, which are putative chromatin modulators involved in higher order chromatin domains [29]. A FLYWCH domain present in C. elegans PEB-1 was shown to be involved in specific DNA binding [52]. The up-regulation of gene Bta02212 exclusively in ToCV whiteflies after the $24 \mathrm{~h}$ AAP hints that high expression of Bta02212, FLYWCH and MULE domain containing protein, may be required for a function associated with whitefly acquisition of ToCV.

Analysis of the 10 most up-regulated genes from ToCV whiteflies at $72 \mathrm{~h}$ and the only two up-regulated genes from $\mathrm{ToCV}$ whiteflies at $48 \mathrm{~h}$ revealed three genes associated with the uric acid pathway. The expression of two genes, Bta15430, uricase and Bta14011, OHCUdecarboxylase (the latter also highly expressed at the $48 \mathrm{~h}$ time point) from the uric acid pathway and one gene (Bta09595, phosphoribosylformylglycinaminde cyclo-ligase) that synthesizes purines and is a precursor for the uric acid pathway, were expressed at a higher rate in ToCV whiteflies compared to VF whiteflies at $72 \mathrm{~h}$ (Table 3). Uric acid is a defense regulator and has been identified as a molecular scavenger of deleterious oxygen free radicals in Drosophila melanogaster [53]. Both genes, Bta15430 (uricase) and Bta14011 (OHCU decarboxylase) play crucial roles in conversion of uric acid to allantoin [28]. The presence of two genes, Bta15430 (Uricase) and Bta14011 (OHCU-decarboxylase) from the uric acid pathway, and a precursor of the uric acid pathway suggest this pathway may be upregulated as part of a defense response in whiteflies fed on ToCV-infected plants. This suggests that even though the virus does not infect the whitefly, the whitefly may be reacting to the virus itself and/or virus-induced changes in tomato sap by mounting a defense response.

The two top most down-regulated genes in ToCV whiteflies at $24 \mathrm{~h}$ were Bta15563 (Vitellogenin-B) and Bta13640 (Chemosensory protein) (Table 4). Vitellogenin-B has been associated with high fecundity, longer lifespan, and a housekeeping role, as well as increased oxidative stress resistance in other insects [32, 33]. However, the reduced expression of Vitellogenin-B, Bta15563 in ToCV whiteflies at $24 \mathrm{~h}$ contradicts the norm of high expression of Vitellogenins in general. The chemosensory protein, Bta13640, is known to be expressed in the antennae of insects, and is involved in sensing environmental signals by triggering chemical-signal transduction. Chemosensory proteins also mediate the solubilization of odorant molecules and facilitate their transport to receptor neurons $[54,55]$. The other most differentially expressed genes in ToCV whiteflies at $24 \mathrm{~h}$ appeared to have housekeeping roles (Vitellogenin-B, Glycerol-3-phosphate dehydrogenase, Heat shock protein
70, Transcription elongation factor B polypeptide 2), while at $72 \mathrm{~h}, 9$ of 10 genes had unknown functions (orphan genes) and most were found to be repeats present in tandem clusters on scaffolds as previously discussed.

\section{KEGG pathway analysis}

KEGG pathway analysis of genes differentially regulated in ToCV whiteflies compared with those in VF whiteflies following a $24 \mathrm{~h}$ AAP revealed upregulation of metabolic pathways, cell growth and death, and the immune system among the top five most affected functional categories (Fig. 2a). A likely explanation for the over-representation of metabolic pathways could be that infection of tomato with $\mathrm{ToCV}$ and its influence on gene expression changes in the plant triggered enhanced feeding desire in the whitefly, and enhanced expression of metabolic genes to support increased feeding activity. The activation of cell growth and death as well as immune system pathways signals a likely defense response of the whitefly to ToCV. Interestingly a higher number of receptor genes (six ECMreceptors down-regulated and two Neuroactive-ligand receptors up-regulated) were significantly differentially regulated in ToCV whiteflies during the $24 \mathrm{~h} \mathrm{AAP} \mathrm{com-}$ pared to only a single receptor gene up-regulated (Type 1 serine/threonine kinase receptor) with the $72 \mathrm{~h}$ AAP (Table 5). Signal transduction and transport and catabolism pathways were the most represented in ToCV whiteflies among down-regulated genes following the $24 \mathrm{~h}$ and $72 \mathrm{~h}$ AAPs, respectively (Figs. 2b and 3b). Notably, a higher number of genes from signal transduction pathways, were down-regulated than up-regulated in ToCV whiteflies following the $24 \mathrm{~h}$ AAP (Additional file 6). Those 54 signal transduction genes down-regulated in ToCV whiteflies were associated with 20 KEGG pathways, including the MAPK signaling pathway (17 genes), phosphatidylinositol 3-kinase (PI3K)-Akt signaling pathway (13 genes), Hippo signaling pathway (11 genes), transforming growth factor- $\beta$ (TGF- $\beta$ ) signaling pathway (three genes), and others (Additional file 6). Interestingly, MAPK and TGF- $\beta$ pathways were also down-regulated in whiteflies during whitefly-begomovirus interactions with Tomato yellow leaf curl China virus (TYLCCNV) [56]. The activity of PI3K-Akt pathway is critical for functionality of some viruses. Influenza A virus requires activation of PI3K-Akt to penetrate host cells, and conversely VP1 protein of foot-and-mouth disease virus inhibits the Akt pathway to promote cell death [57]. Kaposi sarcoma-associated herpesvirus (KSHV) is an oncogenic virus that promotes tumorigenesis through modulating the Hippo pathway [58]. A large number of signal transduction and signaling molecules were down-regulated in $\mathrm{ToCV}$ whiteflies during the $24 \mathrm{~h}$ AAP, whereas few showed differential regulation at $72 \mathrm{~h}$ AAP. This hints at possible 
sensation signals in whitefly as a response to attachment of ToCV to its mouthparts.

The transport and catabolism category was the most represented category (12 genes) identified among the down-regulated genes from $\mathrm{ToCV}$ whiteflies after the 72 h AAP (Table 6). In contrast, 18 genes from the transport and catabolism category were up-regulated in ToCV whiteflies during the $24 \mathrm{~h}$ AAP. Interestingly, 13 lysosome genes were up-regulated in ToCV whiteflies with the $24 \mathrm{~h}$ AAP, whereas a different set of nine lysosome genes were down-regulated in ToCV whiteflies at the $72 \mathrm{~h}$ time point with the exception of two genes. Studies by Luan et al. [56] revealed that genes associated with lysosome function were significantly up-regulated in TYLCCNV-whiteflies, but that study only examined a single time point [56]. Because these RNA-Seq results demonstrated a greater number of lysosome genes activated in $\mathrm{ToCV}$ whiteflies after the $24 \mathrm{~h}$ AAP followed by down-regulation of a largely distinct set of lysosomal genes in ToCV whiteflies after a $72 \mathrm{~h}$ AAP, it can be speculated that up-regulation of lysosomal genes may be an indication of an antiviral response in whiteflies during virus acquisition, whereas down-regulation of a different set of lysosomal genes might be associated with events leading to virus detachment from the whitefly.

Remarkably, 26 out of the total of 33 unique immune system related genes that were classified as belonging to "antigen processing and presentation" pathway were found to be differentially regulated in ToCV whiteflies compared with VF whiteflies, indicating a strong immune response by whitefly to feeding on ToCV infected tomato (Additional file 7). When viruses infect healthy cells of vertebrates, antigen peptide is digested into fragments following presentation of fragmented protein on cell surface MHC molecules (major histocompatibility complex) for recognition and destruction by $\mathrm{T}$ cells [59]. Due to the mounting immune response by healthy cells, viruses evade degradation by cytotoxic $\mathrm{T}$ lymphocytes through the MHC class I antigen processing and presentation pathway $[60,61]$. The expression of the Kaposi's sarcoma-associated herpesvirus (KSHV) related proteins $\mathrm{K} 3$ and $\mathrm{K} 5$ causes the rapid down-regulation of MHC class I molecules from the plasma membrane $[62,63]$. Nef myristoylated protein from HIV-I performs multiple functions in the infection of host cells, including downregulation of MHC class I [64]. The up- and downregulation of genes from the antigen processing and presentation pathway in ToCV whiteflies at $24 \mathrm{~h}$ and $72 \mathrm{~h}$ implied a strong immune response of the whitefly to ToCV, and down-regulation of genes signifies the ability of ToCV to suppress the whitefly's immune response.

KEGG analysis also identified a large number of genes (three up-regulated and 18 down-regulated) implicated in human viral diseases that were differentially regulated in ToCV whiteflies compared to VF whiteflies following $24 \mathrm{~h}$ and $72 \mathrm{~h}$ AAPs. For example, in ToCV whiteflies at $24 \mathrm{~h}$, Bta04024, Wnt protein was significantly upregulated compared to VF whiteflies. Wnt transcription factors inhibit viral replication in Human T-cell leukemia virus type 1 (HTLV-1) [65]. A second gene Bta06242 (Farnesyl pyrophosphate synthase) that showed upregulation in ToCV whiteflies after the $72 \mathrm{~h}$ AAP was shown to interact with human T-cell leukemia virus type proteins [66]. A third gene, Bta04818 (up-regulated in ToCV whiteflies at $72 \mathrm{~h}$ ) is a type I serine/threonine kinase receptor that is also implicated in HTLV-I and Hepatitis-B infection. Through the process of virion binding and entry, viruses are able to manipulate signal transduction pathways either through delivery of viral genes and proteins into infected host cells, or by activating cell surface receptors [67]. Either could be a possible scenario in the case of whitefly interactions with $\mathrm{ToCV}$ because criniviruses have been shown to bind to the mouthparts of the whitefly $[23,68]$ and RNA-Seq data demonstrated activation of genes associated with both signaling pathways and receptors. Of the 18 downregulated genes from $\mathrm{ToCV}$ whiteflies at $24 \mathrm{~h}$ that were previously implicated in human viral diseases, six (Bta00008, Bta09867, Bta02903, Bta03000, Bta08891, Bta08892) were annotated as $70 \mathrm{kDa}$ heat shock proteins (Additional file $4 \mathrm{c} \& \mathrm{~d}$ ). Heat shock cognate protein hsc70 is involved in rotavirus cell entry, in interacting with rotavirus through its peptide-binding domain, and reduces rotavirus infectivity [68]. The $B$. tabaci heat shock protein 70 (HSP70) also responded to the acquisition and retention of two begomoviruses, TYLCV and Squash leaf curl virus [69]. Interestingly, ToCV encodes a HSP70 homolog in its own genome [70] that is a part of the 'rattlesnake tail' structure at the $5^{\prime}$ end of crinivirus genomic RNAs, the same region of the virion that appears to associate with the anterior foregut of vector whiteflies [23, 71, 72].

\section{Conclusions}

Herein, is demonstrated differential regulation of genes in whiteflies fed on ToCV-infected tomato plants compared with whiteflies fed on uninfected tomatoes. DEG analysis demonstrated a temporal shift in gene expression between $24 \mathrm{~h}$ and $72 \mathrm{~h}$ AAPs, but with very few differences between whitefly treatments at $48 \mathrm{~h}$. Differentially regulated genes included a large number of novel orphan genes, genes associated with glucose transporters, $\alpha$-glucosidases, and genes from the uric acid pathway, metabolic pathways, signal transduction pathways, transport and catabolism pathways, immunerelated genes, and candidate receptors. The genes and pathways differentially regulated in whiteflies demonstrate for the first time how a whitefly vector responds physiologically when host plants are infected with a 
semipersistent virus. It is likely that several of the DEGs and differentially regulated pathways contribute to aspects of ToCV acquisition, retention in the vector, and transmission to new host plants during subsequent feeding. This information facilitates further studies on specific interactions determining specificity of crinivirus vector transmission. More broadly, knowledge of vector-virus interactions at a fundamental level is critical to the development of novel genetic control strategies aimed at reducing vector transmission of viruses, and sustainable and effective measures to reduce the spread of whitefly-borne pathogens.

\section{Methods}

\section{Whitefly feeding and RNA isolation}

Bemisia tabaci MEAM1 reared on Brassica oleracea plants were provided acquisition access periods (AAPs) on ToCV-infected or uninfected tomato for periods of 24,48 , and $72 \mathrm{~h}$ [24]. A total of 200-400 whiteflies were collected from ToCV-infected or uninfected tomatoes following 24, 48, and $72 \mathrm{~h}$ AAPs for each of the three biological replications, for a total of 18 samples. Total RNA was purified from each sample using TRIzol (Invitrogen, USA) and the Direct-zol RNA MiniPrep kit (Zymo Research Corporation, USA) following the manufacturers' instructions [24]. The presence of ToCV in plants and whiteflies were confirmed by RT-PCR from each feeding time point, and similarly uninfected plants and VF whiteflies were confirmed virus free by negative RT-PCR results.

\section{Transcriptome sequencing and analysis}

RNA-Seq libraries were constructed from RNA extracted from whiteflies as described above using the paired-end RNA-Seq method [73], sequenced on HiSeq 2500 (Illumina, Inc. USA) and RNA-Seq data was analyzed as described in Chen et al., [24]. Briefly, RNA-Seq raw reads were processed and normalized to FPKM, and differential expression analysis was performed using edgeR. Resulting $p$-values were adjusted for multiple testing using FDR [24]. For the identification of up- or down-regulated genes, the following cutoff parameters were used: genes with $\mathrm{FC}$ ratio $\geq 1.5$ for up-regulated genes and FC ratio $\leq 0.67$ for down-regulated genes. More stringent criteria were used to study individual genes in depth with FPKM $>10$ and fold change $\geq 2$ (up-regulated genes) and $\mathrm{FC} \leq 0.5$ (down-regulated genes) with significant $p$-values $(<0.05)$. The deduced protein sequences of DEGs were used to generate KEGG annotations and pathways using the KEGG database [35].

\section{RT-qPCR}

Total RNA was extracted from whiteflies fed on either ToCV-infected or uninfected tomato for 24,48 , and
$72 \mathrm{~h}$ using the methods and kits that were described for the RNA-Seq method. The RNA was quantified using a NanoDrop spectrophotometer (Thermo Fisher Scientific, USA) and RNA integrity was evaluated by electrophoresis on $2 \%$ agarose gels. Five hundred nanograms of total RNA was reverse transcribed using the QuantiTect Reverse Transcription Kit (Qiagen, USA), followed by PCR using RealMasterMix Probe (5 Prime GmbH, Germany). Each of the PCR reactions included RealMasterMix probe, $0.5 \mu \mathrm{l}$ of $10 \mu \mathrm{M}$ of each forward and reverse primer and TaqMan probe, $2 \mu \mathrm{l}$ of cDNA, and nuclease free water in a total reaction volume of $25 \mu \mathrm{l}$. PCR conditions were as follows: initial denaturation at $98{ }^{\circ} \mathrm{C}$ for 2 min followed by 40 cycles at $98^{\circ} \mathrm{C}$ for $10 \mathrm{~s}$, annealing at $60{ }^{\circ} \mathrm{C}$ for $15 \mathrm{~s}$, and extension at $68{ }^{\circ} \mathrm{C}$ for $20 \mathrm{~s}$. The CFX96 Real Time PCR detection system (Bio-Rad Laboratories, Inc, USA) and CFX manager software were used to normalize expression $(\Delta \Delta \mathrm{Cq})$ for all RT-qPCR assays. The primer pairs and TaqMan probes were designed using Biosearch Technologies, Inc. USA, sequences (Additional file 9). Based on $\mathrm{M}(<1)$ and CV (0.5) values, two novel reference genes were developed: Bta08780 (actin) and Bta13977 (28S ribosomal protein S18a, mitochondrial) that were found to be the most stable reference genes among a set of three reference genes: actin, $28 \mathrm{~S}$ ribosomal protein $\mathrm{S18a}$ mitochondrial, and tubulin. At least three biologically replicated assays were performed. Each RT reaction was loaded in triplicate for RT-qPCR analysis with NRT (no reverse transcriptase) and NTC (no template) controls.

\section{Additional files}

Additional file 1: a The number of Illumina raw and processed reads produced per RNA-Seq library from virus free (VF) whiteflies, Bemisia tabaci MEAM1, and whiteflies fed on Tomato chlorosis virus (ToCV) infected tomato (ToCV) for 24, 48, and 72 h. b Correlation matrix analysis for multiple biological replicates obtained from RNA-Seq libraries prepared from virus free (VF) whiteflies fed on uninfected tomato and whiteflies fed on Tomato chlorosis virus (ToCV) infected tomato for periods of for 24,48 , and $72 \mathrm{~h}$. (XLSX $15 \mathrm{~kb}$ )

Additional file 2: Differentially expressed genes between virus free (VF) whiteflies fed on uninfected tomato and whiteflies fed on Tomato chlorosis virus (ToCV) infected tomato for 24, 48, and 72 h. (XLSX 144 kb)

Additional file 3: a Sixteen orphan genes present on scaffold 1103 that were differentially regulated in ToCV whiteflies compared to virus-free whiteflies. b Non-transcribed genomic hits of Bta00788, orphan gene in the whitefly genome. (XLSX $12 \mathrm{~kb}$ )

Additional file 4: a $\mathrm{KEGG}$ annotation, $\mathrm{KO}$, and score values of the 92 genes out of a total of 447 up-regulated in ToCV whiteflies versus virus-free whiteflies at $24 \mathrm{~h}$. b Pathway reconstruction results from the 92 genes out of a total of 447 up-regulated in ToCV whiteflies versus virus-free whiteflies at $24 \mathrm{~h}$. c KEGG annotation, KO, and score values of the 272 genes out of a total of 542 down-regulated in ToCV whiteflies versus virus-free whiteflies at $24 \mathrm{~h}$. $\mathbf{d}$ Pathway reconstruction results from the 272 genes out of a total of 542 down-regulated in ToCV whiteflies versus virus-free whiteflies at $24 \mathrm{~h}$. (XLSX $72 \mathrm{~kb}$ ) 
Additional file 5: a KEGG annotation, $\mathrm{KO}$, and score values of the 24 genes out of a total of 50 up-regulated in ToCV whiteflies versus virus-free whiteflies at $72 \mathrm{~h}$. b Pathway reconstruction results from the 24 genes out of a total of 50 up-regulated in ToCV whiteflies versus virus-free whiteflies at $72 \mathrm{~h}$. c KEGG annotation, KO, and score values of the 43 genes out of a total of 160 down-regulated in ToCV whiteflies versus virus-free whiteflies at $72 \mathrm{~h}$. d Pathway reconstruction results from the 43 genes out of a total of 160 down-regulated in ToCV whiteflies versus virus-free whiteflies at $72 \mathrm{~h}$. (XLSX $24 \mathrm{~kb})$

Additional file 6: Differential regulation of signal transduction pathways in ToCV whiteflies compared to virus-free (VF) whiteflies at $24 \mathrm{~h}$ and $72 \mathrm{~h}$. (XLSX $15 \mathrm{~kb})$

Additional file 7: Differentially expressed immunity genes significantly regulated in ToCV whiteflies versus VF whiteflies at $24 \mathrm{~h}$ and $72 \mathrm{~h}$ feeding time points. (DOCX $13 \mathrm{~kb}$ )

Additional file 8: RT-qPCR validation of selected genes that were not differentially regulated in ToCV whiteflies after a feeding period of $24 \mathrm{~h}$ compared to virus-free (VF) whiteflies (Bemisia tabaci MEAM1). (DOCX $15 \mathrm{~kb}$ )

Additional file 9: The primer/probe sequences used for validation of RNA-Seq results on selected genes using RT-qPCR. (XLSX $11 \mathrm{~kb}$ )

\section{Abbreviations}

AAP: Acquisition access period; MEAM1: Middle East Asia Minor-1; ToCV whiteflies: Whiteflies fed on ToCV-infected tomato plants; ToCV: Tomato chlorosis virus; VF whiteflies: Whiteflies fed on virus-free or uninfected tomato plants

\section{Acknowledgements}

We thank Arturo A. Cortez for propagation of B. tabaci MEAM1 and ToCV, as well as for conducting whitefly feeding experiments; Laura L. Hladky for validation of virus infection in plants and extraction of RNA from whiteflies; and Wayne B. Hunter for critical review of the manuscript.

\section{Funding}

This work was supported by grants from the USDA ARS Area-wide project to KSL and WMW as a part of the i5K initiative, the USDA-ARS Office of International Research Programs from a grant provided by the USAID Feed-theFuture program (58-0210-3-012) to KSL, WMW and ZF, and USDA-ARS project 2038-22000-013-00D

\section{Availability of data and materials}

The RNA-Seq data is available from the NCBI/GenBank BioProject database under PRJNA312467.

\section{Author's contributions}

NK, DKH, ZF, KSL, and WMW designed research and experimental strategy. NK conducted the experiments. NK, WC, and YZ analyzed the data. NK and WMW drafted manuscript. All authors contributed and gave final approval of the manuscript for publication

\section{Competing interests}

The authors declare that they have no competing interests.

\section{Ethics approval and consent to participate}

Tomato seed cv. Moneymaker used in experimentation was provided by the USDA-ARS Plant Genetic Resources Reseach Unit, Geneva, NY. Bemisia tabaci MEAM1 was collected by USDA-ARS from an infested melon research plot in Imperial Co., CA in 2013 and is maintained at USDA-ARS, Salinas, CA under California Department of Food and Agriculture (CDFA) permit number 2982. The B. tabaci colony was initially confirmed as MEAM1 by J.K. Brown, University of Arizona and C. McKenzie, University of Florida. The colony was validated as MEAM1 immediately prior to experimentation by D. Hasegawa and A. Simmons, USDA-ARS, Charleston, SC. Tomato chlorosis virus (ToCV) was originally collected in 1996 from infected tomato plants in Florida, sequenced (Wintermantel et al., 2005), and deposited in GenBank (AY903447, AY903448). The ToCV isolate is maintained at the USDA-ARS in Salinas, CA under USDA-APHIS permit number P526P-15-03898. All experimentation was conducted per conditions described in CDFA and USDA-APHIS permits. The research described herein does not involve human subjects.

\section{Publisher's Note}

Springer Nature remains neutral with regard to jurisdictional claims in published maps and institutional affiliations.

\section{Author details}

'USDA-ARS, Crop Improvement and Protection Research, 1636 East Alisal Street, Salinas, CA 93905, USA. ²Boyce Thompson Institute, 533 Tower Road, Ithaca, NY 14853-1801, USA. ${ }^{3}$ USDA-ARS, U.S. Vegetable Laboratory, Charleston, 2700 Savannah Highway, Charleston, SC 29414, USA.

Received: 6 January 2017 Accepted: 2 May 2017

Published online: 11 May 2017

\section{References}

1. Oliviera MRV, Henneberry TJ, Anderson P. History, current status, and collaborative research projects for Bemisia tabaci. Crop Prot. 2001;20(9):709-23.

2. Abd-Rabou S, Simmons AM. Survey of Reproductive Host Plants of Bemisia tabaci (Hemiptera: Aleyrodidae) in Egypt. Including New Host Records. Entomol News. 2010;121(5):456-65.

3. Navas-Castillo J, Fiallo-Olive E, Sanchez-Campos S. Emerging virus diseases transmitted by whiteflies. Annu Rev Plant Physiol Plant Mol Biol. 2011:49:219-48.

4. Brown JK, Frohlich DR, Rosell RC. The sweet potato or silverleaf whiteflies: Biotypes of Bemisia tabaci or a species complex? Annu Rev Entomol. 1995;40:511-34.

5. Bedford ID, Briddon RW, Brown JK, Rosell RC, Markham PG. Geminivirus transmission and biological characterisation of Bemisia tabaci (Gennadius) biotypes from different geographic regions. Ann Appl Biol. 1994;125(2):311-25.

6. Boykin LM, Shatters RG, Rosell RC, McKenzie CL, Bagnall RA, De Barro P, Frohlich DR. Global relationships of Bemisia tabaci (Hemiptera: Aleyrodidae) revealed using Bayesian analysis of mitochondrial CO1 DNA sequences. Mol Phylogenet Evol. 2007;44(3):1306-19.

7. De Barro PJ, Liu SS, Boykin LM, Dinsdale AB. Bemisia tabaci: a statement of species status. Annu Rev Entomol. 2011;56:1-19.

8. Dinsdale A, Cook L, Riginos C, Buckley YM, De Barro P. Refined global analysis of Bemisia tabaci (Hemiptera: Sternorrhyncha: Aleyrodoiea: Aleyrodidae) mitochondrial cytochrome oxidase I to identify species level genetic boundaries. Ann Entomol Soc Am. 2010;103(2):196-208.

9. Jones DR. Plant viruses transmitted by whiteflies. Eur J Plant Pathol. 2003; 109(3):195-219.

10. Liu SS, De Barro PJ, Xu J, Luan JB, Zang LS, Ruan YM, Wan FH. Asymmetric mating interactions drive widespread invasion and displacement in a whitefly. Science. 2007;318(5857):1769-72.

11. Xu J, Liu SS, De Barro P. Reproductive incompatibility among genetic groups of Bemisia tabaci supports the proposition that the whitefly is a cryptic species complex. Bull Entomol Res. 2010;100(3):359-66.

12. Zang L-SCW-QLS-S. Comparison of performance on different host plants between the $B$ biotype and a non-B biotype of Bemisia tabaci from Zhejiang, China. Entomol Exp Appl. 2006;121(3):221-7.

13. Alemandri V, Vaghi Medina CG, Dumon AD, Arguello Caro EB, Mattio MF, Garcia Medina S, Lopez Lambertini PM, Truol G. Three members of the Bemisia tabaci (Hemiptera: Aleyrodidae) cryptic species complex occur sympatrically in Argentine horticultural crops. J Econ Entomol. 2015;108(2):405-13.

14. Bellows TS, Perring TM, Gill RJ, Headrick DH. Description of a Species of Bemisia (Homoptera: Aleyrodidae). Ann Entomol Soc Am. 1994;87(2):195-206.

15. Perring TM. The Bemisia tabaci species complex. Crop Prot. 2001;20(9):725-37

16. Gray SM, Banerjee N. Mechanisms of arthropod transmission of plant and animal viruses. Microb Molec Biol Rev. 1999;63(1):128-48.

17. Czosnek H, Ghanim M, Ghanim M. The circulative pathway of begomoviruses in the whitefly vector Bemisia tabaci-insights from studies with Tomato yellow leaf curl virus. Ann Appl Biol. 2002:140:215-31.

18. Cicero JM, Brown JK. Bemisia tabaci-mediated transmission of begomoviruses: history and anatomical, biological, and cellular interactions. In: Brown JK, editor. Vector-Mediated Transmission of Plant Pathogens. St. Paul: APS Press; 2016. p. 211-30.

19. Wintermantel WM. Semipersistent whitefly-transmitted viruses: Criniviruses. In: Brown JK, editor. Vector-Mediated Transmission of Plant Pathogens. St. Paul: APS Press; 2016. p. 111-9.

20. $\mathrm{Ng} \mathrm{JC}$, Falk BW. Bemisia tabaci transmission of specific Lettuce infectious yellows virus genotypes derived from in vitro synthesized transcriptinoculated protoplasts. Virology. 2006;352:209-15. 
21. Stewart LR, Medina V, Tian T, Turina M, Falk BW, Ng JC. A mutation in the Lettuce infectious yellows virus minor coat protein disrupts whitefly transmission but not in planta systemic movement. J Virol. 2010;84: 12165-73.

22. Chen AY, Walker GP, Carter D, Ng JC. A virus capsid component mediates virion retention and transmission by its insect vector. Proc Natl Acad Sci U S A. 2011;108:16777-82.

23. Tian T, Rubio L, Yeh HH, Crawford B, Falk BW. Lettuce infectious yellows virus: in vitro acquisition analysis using partially purified virions and the whitefly Bemisia tabaci. J Gen Virol. 1999;80(Pt 5):1111-7.

24. Chen W, Hasegawa DK, Kaur N, Kliot A, Pinheiro PV, Luan J, Stensmyr MC, Zheng Y, Liu W, Sun H, Xu Y, Luo Y, Kruse A, Yang X, Kontsedalov S, Lebedev G, Fisher TW, Nelson DR, Hunter WB, Brown JK, Jander G, Cilia M, Douglas AE, Ghanim M, Simmons AM, Wintermantel WM, Ling K-S, Fei Z. The draft genome of whitefly Bemisia tabaci MEAM1, a global crop pest, provides novel insights into virus transmission, host adaptation, and insecticide resistance. BMC Biol. 2016;14:110. doi:10. 1186/s12915-016-0321-y.

25. Tautz D, Domazet-Lošo T. The evolutionary origin of orphan genes. Nat Rev Genet. 2011;12(10):692-702.

26. Khalturin K, Georg Hemmrich G, Sebastian Fraune S, René Augustin R, Bosch TCG. More than just orphans: are taxonomically-restricted genes important in evolution? Trends Genet. 2009;25(9):404-13.

27. McLysaght A, Guerzoni D. New genes from non-coding sequence: the role of de novo protein-coding genes in eukaryotic evolutionary innovation. Phil Trans R Soc B. 2016;370(1678):20140332.

28. Ramazzina I, Folli C, Secchi A, Berni R, Percudani R. Completing the uric acid degradation pathway through phylogenetic comparison of whole genomes. Nat Chem Biol. 2006;2(3):144-8.

29. Dorn R, Krauss $\mathrm{V}$. The modifier of mdg4 locus in Drosophila: functional complexity is resolved by trans splicing. Genetica. 2003;117(2):165-77.

30. Babu MM, Iyer LM, Balaji S, Aravind L. The natural history of the WRKY-GCM1 zinc fingers and the relationship between transcription factors and transposons. Nucleic Acids Res. 2006;34(22):6505-20.

31. Maiuolo J, Oppedisano F, Gratteri S, Muscoli C, Mollace V. Regulation of uric acid metabolism and excretion. Int J Cardiol. 2016;213:8-14.

32. Zubrzycki IZ, Lee S, Lee $K$, Wiacek M, Lee W. The study on highly expressed proteins as a function of an elevated ultraviolet radiation in the copepod, Tigriopus japonicas. Open Sci J. 2012;47(2):75-82.

33. Kent CF, Issa A, Bunting AC, Zayed A. Adaptive evolution of a key gene affecting queen and worker traits in the honey bee, Apis mellifera. Mol Ecol. 2011;20(24):5226-35.

34. Forêt S, Wanner KW, Maleszka R. Chemosensory proteins in the honey bee: Insights from the annotated genome, comparative analyses and expressional profiling. Insect Biochem Mol Biol. 2007;37:19-28.

35. Kanehisa M, Sato Y, Morishima K. BlastKOALA and GhostKOALA: KEGG tools for functional characterization of genome and metagenome sequences. J Mol Biol. 2016;428(4):726-31.

36. Wintermantel WM, Wisler GC. Vector specificity, host range, and genetic diversity of Tomato chlorosis virus. Plant Dis. 2006;90(6):814-9.

37. Gibson AK, Smith Z, Fuqua C, Clay K, Colbourne JK. Why so many unknown genes? Partitioning orphans from a representative transcriptome of the lone star tick Amblyomma americanum. BMC Genomics. 2013;14(1):135.

38. Colbourne JK, Pfrender ME, Gilbert D, Thomas WK, Tucker A, Oakley TH, Tokishita S, Aerts A, Arnold GJ, Basu MK, Bauer DJ, Cáceres CE, Carmel L, Casola C, Choi JH, Detter JC, Dong Q, Dusheyko S, Eads BD, Fröhlich T, Geiler-Samerotte KA, Gerlach D, Hatcher P, Jogdeo S, Krijgsveld J, Kriventseva EV, Kültz D, Laforsch C, Lindquist E, Lopez J, Manak JR, Muller J, Pangilinan J, Patwardhan RP, Pitluck S, Pritham E, Rechtsteiner A, Rho M, Rogozin IB, Sakarya O, Salamov A, Schaack S, Shapiro H, Shiga Y, Skalitzky C, Smith Z, Souvorov A, Sung W, Tang Z, Tsuchiya D, Tu H, Vos H, Wang M, Wolf Yl, Yamagata H, Yamada T, Ye Y, Shaw JR, Andrews J, Crease TJ, Tang H, Lucas SM, Robertson HM, Bork P, Koonin EV, Zdobnov EM, Grigoriev IV, Lynch M, Boore JL. The ecoresponsive genome of Daphnia pulex. Science. 2011;331(6017):555-61.

39. Kuo C-H, Kissinger J-C. Consistent and contrasting properties of lineagespecific genes in the apicomplexan parasites Plasmodium and Theileria. BMC Evol Biol. 2008;8:108.

40. Zhao L, Saelao P, Jones CD, Begun DJ. Origin and spread of de novo genes in Drosophila melanogaster populations. Science. 2014;343(6172):769-72

41. Heinen TJAJ, Staubach F, Haming D, Tautz D. Emergence of a new gene from an intergenic region. Curr Biol. 2009;19(18):1527-31.
42. Wissler L, Gadau J, Simola DF, Helmkampf M, Bornberg-Bauer E. Mechanisms and dynamics of orphan gene emergence in insect genomes. Genome Biol Evol. 2013;5(2):439-55.

43. Domazet-Loso T, Tautz D. An evolutionary analysis of orphan genes in Drosophila. Genome Res. 2003;13(10):2213-9.

44. Yang Z, Huang J. De novo origin of new genes with introns in Plasmodium vivax. FEBS Lett. 2011;585:641-4.

45. Huang HT, Chan HL, Shih TY, Chen LL. A study of the role of glucose transporter 1 (Glut1) in white spot syndrome virus (WSSV) infection. Fish Shellfish Immunol. 2015;46(2):305-14.

46. Tailor CS, Willett BJ, Kabat D. A putative cell surface receptor for anemiainducing feline leukemia virus subgroup $C$ is a member of a transporter superfamily. J Virol. 1999:73(8):6500-5.

47. Sorbara IR, Maldarelli F, Chamoun G, Schilling B, Chokekijcahi S, Staudt L, Mitsuya H, Simpson IA, Zeichner SL. Human Immunodeficiency Virus Type 1 Infection of H9 Cells Induces Increased Glucose Transporter Expression. J Virol. 1996:70(10):7275-9.

48. Yu Y, Maguire TG, Alwine JC. Human Cytomegalovirus Activates Glucose Transporter 4 Expression To Increase Glucose Uptake during Infection. J Virol. 2011;85(4):1573-80

49. Henrissat B, Callebaut I, Fabrega S, Lehn P, Mornon JP, Davies G. Conserved catalytic machinery and the prediction of a common fold for several families of glycosyl hydrolases. Proc Natl Acad Sci U S A. 1995;92(15):7090-4.

50. Walker BD, Kowalski M, Goh WC, Kozarsky K, Krieger M, Rosen C, Rohrschneider L, Haseltine WA, Sodroski J. Inhibition of human immunodeficieny virus syncytium formation and virus replication by castanospermine. Proc Natl Acad Sci U S A. 1987;84(22):8120-4.

51. Mehta A, Zitzmann N, Rudd PM, Block TM, Dwek RA. a-Glucosidase inhibitors as potential broad based anti-viral agents. FEBS Lett. 1998;430(1-2):17.

52. Thatcher JD, Fernandez AP, Beaster-Jones L, Haun C, Okkema PG. The Caenorhabditis elegans peb-1 gene encodes a novel DNA-binding protein involved in morphongenesis of the pharynx, vulva, and hindgut. Dev Biol. 2001;229(2):480-93.

53. Hilliker AJ, Duyf B, Evans D, Phillips JP. Urate-null rosy mutants of Drosophila melanogaster are hypersensitive to oxygen stress. Proc Natl Acad Sci U S A. 1992:89(10):4343-7.

54. Gu SH, Wang SY, Zhang XY, Ji P, Liu JT, Wang GR, Wu KM, Guo YY, Zhou JJ, Zhang YJ. Functional characterizations of chemosensory proteins of the alfalfa plant bug Adelphocoris lineolatus indicate their involvement in host recognition. PLoS. 2012;7(8):e42871.

55. Campanacci V, Lartigue A, Martin Hallberg B, Jones TA, Giudici-Orticoni MT, Mariella Tegoni M, Cambillau C. Moth chemosensory protein exhibits drastic conformational changes and cooperativity on ligand binding. Proc Natl Acad Sci U S A. 2003;100(9):5069-74.

56. Luan JB, Li JM, Varela N, Wang YL, Li FF, Bao YY, Zhang CX, Liu SS, Wang $\mathrm{XW}$. Global analysis of the transcriptional response of whitefly to Tomato yellow leaf curl China virus reveals the relationship of coevolved adaptations. J Virol. 2011;85(7):3330-40.

57. Ji WT, Liu HJ. PI3K-Akt signaling and viral infection. Recent Pat Biotechnol. 2008;2(3):218-26.

58. Liu G, Yu FX, Kim YC, Meng Z, Naipauer J, Looney DJ, Liu X, Gutkind JS, Mesri EA, Guan KL. Kaposi sarcoma-associated herpesvirus promotes tumorigenesis by modulating the Hippo pathway. Oncogene. 2015;34(27): 3536-46.

59. Blum JS, Wearsch PA, Cresswell P. Pathways of Antigen Processing. Annu Rev Immunol. 2013:31:443-73.

60. Hewitt EW. The MHC, class I antigen presentation pathway: strategies for viral immune evasion. Immunology. 2003;110(2):163-9.

61. Hansen TH, Bouvie M. MHC class I antigen presentation: learning from viral evasion strategies. Nat Rev Immunol. 2009;9: 503-13.

62. Ishido S, Wang C, Lee BS, Cohen GB, Jung JU. Downregulation of major histocompatibility complex class I molecules by Kaposi's sarcoma-associated herpesvirus K3 and K5 proteins. J Virol. 2000;74:5300-9.

63. Coscoy L, Ganem D. Kaposi's sarcoma-associated herpesvirus encodes two proteins that block cell surface display of MHC class I chains by enhancing their endocytosis. Proc Natl Acad Sci U S A. 2000;97:8051-6.

64. Arora VK, Fredericksen BL, Garcia JV. Nef. agent of cell subversion. Microbes Infect. 2002:4:189-99.

65. Ma G, Yasunaga Jl, Akari H, Matsuoka M. TCF1 and LEF1 act as T-cell intrinsic HTLV-1 antagonists by targeting Tax. Proc Natl Acad Sci U S A. 2015;112(7):2216-21. 
66. Lefebvre L, Vanderplasschen A, Ciminale V, Heremans H, Dangoisse O, Jauniaux JC, Toussaint JF, Zelnik V, Burny A, Kettmann R, Willems L.

Oncoviral bovine leukemia virus G4 and human T-cell leukemia virus type 1 p13(II) accessory proteins interact with farnesyl pyrophosphate synthetase. J Virol. 2002;76(3):1400-14. doi:10.1128/JVI.76.3.1400-1414.2002.

67. Greber UF. Signalling in viral entry. Cell Mol Life Sci. 2002;59(4):608-26.

68. Pérez-Vargas J, Romero P, López S, Arias CF. The peptide-binding and ATPase domains of recombinant hsc70 are required to interact with rotavirus and reduce its infectivity. J Virol. 2006;80(7):3322-31.

69. Götz M, Popovski S, Kollenberg M, Gorovits R, Brown JK, Cicero JM, Czosnek H. Winter S, Ghanim M. Implication of Bemisia tabaci Heat Shock Protein 70 in Begomovirus-Whitefly Interactions. J Virol. 2012;86(24):13241-52.

70. Wintermantel WM, Wisler GC, Anchieta AG, Liu H-Y, Karasev AV, Tzanetakis IE. The complete nucleotide sequence and genome organization of Tomato chlorosis virus. Arch Virol. 2005:150(11):2287-98.

71. Peremyslov W, et al. Complex molecular architecture of beet yellows virus particles. Proc Natl Acad Sci U S A. 2004;101:5030-5.

72. Satyanarayana T, Gowda S, Ayllón MA, Dawson WO. Closterovirus bipolar virion: evidence for initiation of assembly by minor coat protein and its restriction to the genomic RNA 5' region. Proc Natl Acad Sci U S A. 2004;101:799-804.

73. Zhong S, et al. High-throughput illumina strand-specific RNA sequencing library preparation. Cold Spring Harb Protoc. 2011;8:940-9.

\section{Submit your next manuscript to BioMed Central} and we will help you at every step:

- We accept pre-submission inquiries

- Our selector tool helps you to find the most relevant journal

- We provide round the clock customer support

- Convenient online submission

- Thorough peer review

- Inclusion in PubMed and all major indexing services

- Maximum visibility for your research

Submit your manuscript at www.biomedcentral.com/submit 